Portland State University

PDXScholar

Spring 7-6-2016

\title{
Biofouling Management in the Pacific Northwest and Predation on Native versus Non-native Ascidians
}

\author{
Erin Suzanne Kincaid \\ Portland State University
}

Follow this and additional works at: https://pdxscholar.library.pdx.edu/open_access_etds

Part of the Marine Biology Commons, and the Terrestrial and Aquatic Ecology Commons Let us know how access to this document benefits you.

\section{Recommended Citation}

Kincaid, Erin Suzanne, "Biofouling Management in the Pacific Northwest and Predation on Native versus Non-native Ascidians" (2016). Dissertations and Theses. Paper 3069.

https://doi.org/10.15760/etd.3067

This Thesis is brought to you for free and open access. It has been accepted for inclusion in Dissertations and Theses by an authorized administrator of PDXScholar. Please contact us if we can make this document more accessible: pdxscholar@pdx.edu. 
Biofouling Management in the Pacific Northwest and Predation on

Native versus Non-native Ascidians

$$
\text { by }
$$

Erin Suzanne Kincaid

A thesis submitted in partial fulfillment of the requirements for the degree of

\author{
Master of Science \\ in \\ Environmental Science Management
}

Thesis Committee:

Catherine de Rivera, Chair

Angela Strecker

Gregory Ruiz

Portland State University

2016 


\begin{abstract}
Marine non-native species threaten economic and environmental health, making it crucial to understand factors that make them successful. Research on these species, therefore, allows for greater preparedness and informed management of biological invasions and increases understanding of elements structuring biological communities. Among the marine non-native species, and particularly the fouling community, nonnative ascidians are a taxon of particular concern because they can crowd out native benthic species and smother mariculture products. This thesis addresses management for ascidians and other fouling organisms and includes research on the invasiveness of this taxon in addition to the invasibility of recipient fouling communities. On the West Coast of the U.S., limited efforts have been made to coordinate biofouling management across states, despite the myriad vectors increasing propagule pressure over time along coastal states. Building on recent state and local efforts, I developed a Pacific Regional Biofouling Plan for the states of Oregon and Washington to help start a consensus-driven process by which these states could create a forum for more comprehensive coordination efforts, following California's lead. As states address authority gaps, the biofouling management framework I've written is meant to be used to guide the conversation between managers as various stages of coastal management are realized.

To better inform the scope and efficacy of management and regulatory efforts, the study of invasions ecology asks and aims to answer questions regarding recipient community interactions and characteristics of the non-native species themselves. Studies that identify characteristics that make ascidians successful (invasiveness) and determine
\end{abstract}


the influence native communities have on their success (invasibility) are important for assessing overall risk of establishment and spread from non-native ascidians. Therefore, I aimed to: 1) explore the hypothesis that fouling communities on suspended, artificial structures are more invasible than benthic habitats; and 2) identify characteristics influencing predation patterns on the native Distaplia occidentalis versus non-native ascidian species using mensurative and experimental studies in Charleston Marina, Oregon. I conducted a series of feeding assays, surveys, and a caloric content analysis. Feeding assays were conducted with a suite of predators. The flatworm predator (Eurylepta leoparda) was found to be highly selective on the native ascidian Distaplia occidentalis, and only preyed on whole colony samples. Feeding assay data suggest that test (tunic) structure or thickness may be an influential factor affecting nudibranch (Hermissenda crassicornis) predation rates on native versus non-native ascidians, with greater predation on the native ascidian species. Non-native ascidians may escape predation in floating but not benthic environments on the Oregon coast due to their palatability characteristics, likely tunic structure and low caloric content. In this case, this suite of predators may indirectly facilitate the invasion of docks but provide at least partial resistance to the invasion of natural benthic areas.

The chapters herein address gaps in management and scientific knowledge regarding non-native species of the marine fouling community. Future work enhanced by my efforts could include the development of the coastal biofouling management plan, coordinated by the Western Regional Panel on Aquatic Invasive Species Coastal Committee, and broadening the geographic and taxonomic scope of my research with a more comprehensive study of predator-prey interactions involving non-native ascidians 
and a diverse suite of predators. These interactions may be an important factor in explaining the success of ascidians and other fouling organisms on floating structures and lack of success on nearby benthic substrata. 


\section{Acknowledgements}

I would like to express my sincere gratitude to Dr. Catherine de Rivera for welcoming me to her laboratory and for her support throughout my graduate work, including innumerable comments (at any hour) on my plans, ideas, and writing. I thank the U.S. Fish and Wildlife Service for their support and the opportunity to work for the Pacific Regional Office while completing the Regional Biofouling Management Plan, the development of which would not have been possible without the astute guidance of my supervisor, Robyn Draheim. Thank you to Ian Davidson for comments and for providing documentation and survey questions for the Oregon boater behavior survey. Thank you to Glenn Dolphin for working with Charleston Marina and others to distribute the survey. I am also grateful to the Western Regional Panel Coastal Committee for comments on the biofouling management framework. The development of this framework was enhanced by contributions from my fellow students Sydney Gonsalves, Whitney McClees, and Kelton Rappleyea, to whom I give thanks. I greatly appreciate everyone who assisted me in my research efforts including all members of the de Rivera laboratory, Dr. Amy Larson, Dr. Martin Lafrenz, Kimberly Gottschalk, and Kimberly Hack. Dr. Craig Young and his students, I must sincerely thank for being such gracious hosts and sources of information at the Oregon Institute of Marine Biology. Thank you to the Pacific Estuarine Research Society for funding this research project through the Eldridge Memorial Fund. Finally, thank you to my committee members, including Dr. Angela Strecker and Dr. Greg Ruiz for their insightful comments. 


\section{Table of Contents}

Abstract......................................................... i

Acknowledgements................................................. iv

List of Tables....................................................... vii

List of Figures.......................................................

Chapter 1: Introduction.............................................. 1

Chapter 2: Pacific Regional Biofouling Management Plan.................... 13

Introduction............................................... 14

Vectors..................................................22

Assessment of Vector Operations............................... 27

Biofouling Management Framework........................... 30

Prevention........................................... 31

Early Detection....................................... 36

Survey/Monitoring ..................................... 38 
Control............................................. 48

Conclusion.................................................51

Chapter 3: Prey structure, caloric content, and predator characteristics influence predation rates on native versus non-native ascidians.

Introduction................................................54

Methods.....................................................60

Results..................................................70

Discussion....................................................... 81

Conclusion.................................................86

Chapter 4: Conclusion............................................... 89

References...................................................... 93

Appendix A: Oregon Boater Behavioral Questionnaire........................... 106

Appendix B: Fouling Control Options Chart............................... 109 


\section{List of Tables}

Table 1: One-way ANOVA results with caloric content (calories/g of dry weight) of ascidian samples, spanning 6 species, as response testing the influence of ascidian type (solitary or colonial).

Table 2: One-way ANOVA results with caloric content (calories/g of dry weight) of ascidian samples, spanning 6 species, as response testing the influence of native versus non-native ascidian type.

Table 3: Results of whole colony, blended in squid paste, and chemical extract in squid paste ascidian feeding assay t-tests comparing native and non-native prey including tstatistic, $p$-value, mean predation rate on each ascidian species $+/$ - standard error....75

Table 4: Two-way ANOVA results with feeding rates ( $\mathrm{mg} / \mathrm{hr}$, sqrt) as response, time block included as a random factor and predator species nested in habitat of predator as a factor (benthic or suspended), the other factor being ascidian prey type (native or nonnative).... .76

Table 5: Post-hoc Tukey's HSD with pairwise comparisons of feeding rates for ascidian prey (native or non-native) and habitat of predator (benthic or suspended) as factors. .76

Table 6: Predator size distribution data across prey category for each assay and predator (with available data); ANOVA results show no influence of prey category (native or nonnative) on predator size distribution in the assays .81 


\section{List of Figures}

Figure 1: Schematic of feeding assay study design showing one predator and one ascidian sample paired per tank across 24 total tanks, 6 tanks per predator times 4 time blocks. Design is for 3 separate feeding assays including whole colony ascidian samples (native or non-native), blended samples in squid paste, chemical extracts in squid paste.....68

Figure 2: Mean caloric content, + or -1 standard error, of native ascidian (blue) Distaplia occidentalis $(\mathrm{n}=5)$ and non-native ascidian (light grey) Botrylloides violaceus $(\mathrm{n}=5)$.

Figure 3: Whole colony feeding assay rates $(\mathrm{mg} / \mathrm{hr})$ across four predators, two found on suspended substrata (Hermissenda crassicornis, $\mathrm{n}=17$ and Eurylepta leoparda, $\mathrm{n}=6$ ) and two not found on suspended substrata and only found in the benthic habitat (Pagurus granosimanus, $\mathrm{n}=16$ and Hemigrapsus oregonensis, $\mathrm{n}=12$ ). Feeding rates shown are all relative to the change in corresponding control treatments. Bars show means \pm 1 standard error.

Figure 4: Blended ascidian mixed with squid paste feeding assay rates (mg/hr) across three predators, one found on suspended substrata (Hermissenda crassicornis, $\mathrm{n}=9$ ) and two benthic (Pagurus granosimanus, $\mathrm{n}=12$ and Hemigrapsus oregonensis, $\mathrm{n}=12$ ). Feeding rates shown are all relative to the change in corresponding control treatments. Bars show means \pm 1 standard error......................................... 78

Figure 5: Ascidian chemical extracts mixed with squid paste feeding assay rates $(\mathrm{mg} / \mathrm{hr})$ across three predators, one found on suspended substrata (Hermissenda crassicornis, $\mathrm{n}=9$ ) and two benthic (Pagurus granosimanus, $\mathrm{n}=12$ and Hemigrapsus oregonensis, $\mathrm{n}=12$ ). Feeding rates shown are all relative to the change in corresponding control treatments. Bars show means \pm 1 standard error............................... 79

Figure 6: Interaction plot of two-way ANOVA including ascidian prey identity (native or non-native) and habitat of predator (benthic or suspended) as factors; feeding rate $\mathrm{mg} / \mathrm{hr}$,

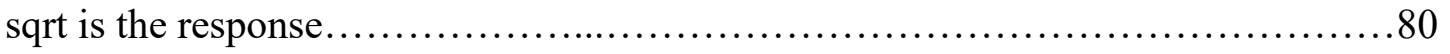

Figure 7: Linear relationship between shore crab (Hemigrapsus oregonensis) size (carapace width $\mathrm{mm}$ ) and feeding rates $(\mathrm{mg} / \mathrm{hr}$ ).... 


\section{Chapter 1: Introduction}

Marine non-native species threaten marina infrastructure and coastal ecosystem health (Bax et al. 2003), presenting unique challenges to managers and opportunities to test the ecological function of natural communities (Sax et al. 2007). Environmental threats from marine non-native species include the spread of species that outcompete their native counterparts (Tyrrell \& Byers 2007). The spread of colonial fouling organisms (organisms that attach to and grow on hard substrate) is of particular concern as they have been shown to overgrow native seaweeds, seagrasses, and bivalves in thick mats, altering community composition and potentially reducing food accessibility for predators, such as fish (Valentine et al. 2007, Lengyel et al. 2009). Economic threats include non-native species that significantly impact marina infrastructure and aquaculture operations by damaging equipment and reducing growth of product species (Aldred \& Clare 2013, Davidson 2012). The impacts associated with marine invasive species are projected to worsen as waters warm and vector-associated risks increase through globalization (Occhipinti-Ambrogi 2007). It is, therefore, essential to build on existing non-native species management frameworks to address these issues directly and to conduct studies with the ultimate goal of enhancing management approaches while simultaneously elucidating ecosystem function. Historical context from management and ecological perspectives on non-native marine species will provide insight to the knowledge gaps my work has addressed. 
The transfer of non-native fouling organisms to new habitats is largely attributed to shipping, even in the industry's early years when vessels were wood and used dry ballast (Ruiz et al. 2015). Early ships transported organisms including shipworms, arthropods, plants, mollusks, and other fouling species (Carlton 1989). Transoceanic shipping and the transport of these organisms began prior to most biological surveys of fouling fauna, so early surveys likely reflect fouling communities that had already been altered by human movement (Carlton 1989). In the early 1900s ships transitioned from dry ballast to using water for stability. This sea water ballast often contains up to 250 species (Gollasch et al. 2002), some of which may be fouling species as free-floating larvae. While independent levels of contribution for the ballast water and hull fouling vectors is unknown, shipping as a vector has been found to contribute between $44-78 \%$ of non-native species introductions in North America (Ruiz et al. 2015). Other vectors such as aquaculture, recreational boating, and marine debris are also concerns in the management of marine non-native species, as the movement of aquaculture equipment and recreational boats are not regulated (Davidson et al. 2010, Davidson et al. 2014, Murray et al. 2011). The multitude of non-native fouling vectors require comprehensive and coordinated management.

The challenge of addressing marine non-native species from a management perspective lies in the fact that these vectors are not only largely unregulated, they also change in intensity through time and geographies. Both detection and invasion rates are known to be increasing due to greater detection efforts and enhanced technologies, as well as growing global trade through shipping (Ruiz et al. 2015). For example, in San 
Francisco Bay, from the mid-1800s through the 1950s, an average of one new species was introduced every 55 weeks; from the 1960s-1995, this increased to one new species introduction every 14 weeks (Cohen \& Carlton 1998). Despite obvious increases in detected introductions, it is understood that most studies estimating introductions in the marine environment are underestimates due to current and historical limits to survey efforts and the difficulty in identifying non-indigenous species (Ruiz et al. 2015), further challenging comprehensive management efforts. Vector hubs are typically in bays and estuaries where most marine non-native species are found; few non-natives are found on the open coast (Wasson et al. 2005, Priesler et al. 2009, Ruiz et al. 2009). These estuarine areas are, in many cases, experiencing increased human activity and, therefore, increased introductions.

Despite these dynamic challenges, some progress toward the management of vectors, especially ballast water, has been made. This progress has been due to the heightened concern for spread of non-native fouling organisms (Ruiz \& Carlton 2003). This increased concern may be due, in part, to invasions of non-native tunicates (ascidians), which damage marine infrastructure and native benthic communities (Lambert 2007). In order to reduce introductions through ballast water, the International Marine Organization (IMO) has called for mid-ocean ballast water exchange and proposed treatment of ballast water (Albert et al. 2013). The U.S. Coast Guard and the Environmental Protection Agency have also made moves toward concentration-based discharge standards, requiring the treatment of ballast water to reduce live organism numbers (Albert et al. 2013), although further research elucidating the risk-release 
relationship is needed for effective discharge standards (Bailey 2015). Due to new U.S. Coast Guard regulations (33 CFR 151.2025), no vessel in U.S. waters may discharge ballast water without use of an approved ballast water management system, offering a framework from which states may also coordinate regulation of ballast water.

Although progress has been made toward management of ballast water, minimal coordinated regulatory efforts have been directed toward hull fouling as a vector of nonnative species (Ruiz et al. 2015). Shipping is the strongest vector of introduction in California, which has been identified as a source of spread along West Coast states, making it a priority for proactive management efforts (Ruiz et al. 2011), including hull fouling regulation. In 2006, the state of California released an official report on the risk of commercial vessel hull fouling, required by the state Marine Invasive Species Act of 2003. The report provided recommendations and requested regulatory power to require hull cleanings and reporting of hull cleaning practices (Takata et al. 2006). The reporting requirements for hull cleaning practices were successfully enacted. At present, commercial vessel hull cleaning is voluntary and largely executed based on the economic incentive of reduced drag and, therefore, reduced fuel costs (Shultz et al. 2011). However, niche areas like sea chests and propellers are often overlooked during these cleanings, and regulatory standards are still lacking. Though the state has regulatory authority over commercial vessels, other vectors such as fishing and recreational vessels are unregulated and regulatory power is unassigned, leaving risk of introductions to and from California. Assessment of the risk of these vectors concluded that the risk posed warrants management and regulatory attention (Davidson et al. 2012). Other West Coast 
states have made moves toward managing non-native fouling species, although these have been primarily retroactive. Following the invasions of several problematic tunicate species, Washington state developed a management plan to address the negative impacts of these species (Pleus et al. 2008). The state of Oregon has been monitoring and has authorized and supported removal efforts of the nuisance species Didemnum vexillum. Both states have published reports on vector activities and existing regulatory frameworks regarding biofouling management, although Oregon's report is focused on shipping traffic (Davidson et al. 2014, Paul 2011).

With these efforts and the reaction to recent invasions, there is obvious momentum behind the management of non-native fouling species on the West Coast. The Pacific Ballast Water Group and the Western Regional Panel (WRP) Coastal Committee have discussed the issues of hull fouling in recent years (Western Regional Panel on Aquatic Nuisance Species 2014). Dr. Catherine de Rivera presented on the topic of a multi-state biofouling management plan to the WRP Coastal Committee in August of 2014, and the topic was well received. I presented on this topic in April of 2015, with respect to the states of Oregon and Washington, and the progress I had made up to that point. At this meeting, the WRP Coastal Committee agreed to the development of a comprehensive coastal biofouling management plan. Here is an opportunity to make the suggestion of regional, vector-focused management offered by Ruiz \& Carlton (2003) a reality.

A variety of management plans for states, countries, and sometimes regions provide models for a multispecies approach, and for vector management. Australia's 
National System for the Prevention and Management of Marine Pest Incursions (Commonwealth of Australia 2013) offers a good model of vector management by allowing a specific agency to address ballast water, hull fouling, and the aquarium trade (although hull fouling is still largely voluntary). New Zealand takes preventative action a step further through the 'Craft Risk Management Standard: Biofouling on Vessels Arriving in New Zealand' which, in 2018, will enforce a clean hull standard for all vessels entering New Zealand waters and vessels belonging to New Zealand waters that travel internationally (Thomson 2014). These systems target multiple fouling species by focusing attention on shipping and recreational boating vectors. State examples include Washington's Aquatic Nuisance Species plan that addresses multiple freshwater species and develops lines of communication across the state (Meacham 2001). Although nonnative species are not limited by state lines, surprisingly few coordinated regional efforts have been made in the U.S. to address non-native species. Successful management models include the West Coast Governor's Agreement Spartina Eradication Work Plan (WCGA 2010), addressing existing incursions, and the Regional Biosecurity Plan for Micronesia \& Hawaii (Ruiz et al. 2014), addressing risks of incursion for multiple species.

The management plan I have written for the states of Oregon and Washington was intended to help start a consensus-driven process by which the coastal states could come together and create a forum for more comprehensive coordination efforts. Like with ballast water, OR and WA often look to CA to follow their lead and this document reflects an attempt to provide clarification on OR and WA authorities, rules, and actual 
on-the-ground efforts to manage biofouling. It also offers a science-based framework, in an issue/recommendation format, which the WRP Coastal Committee may use to guide the development of the comprehensive coastal plan. All such management efforts require a strong comprehension of the invasions ecology of non-native fouling species and native communities.

With the potential to inform the scope and efficacy of management and regulatory efforts, the study of invasions ecology asks and aims to answer questions regarding recipient community interactions and characteristics of the non-native species themselves. In 1958, Charles Elton published the pivotal work "The Ecology of Invasions by Animals and Plants" which outlined the theory behind non-native species and recipient communities. Since then, our understanding of how to assess species invasiveness (how invasive a species is; Kolar \& Lodge 2001) and community invasibility (how susceptible the recipient community is to invasion; Levine \& D’Antonio 1999) has grown more robust, and the practical applications associated with the discipline of invasions ecology have grown. Each of these factors is a component of the biotic interactions that influences the success of propagules (any individual or fragment capable of growth and the production of new individuals) of non-native species, provided that abiotic conditions do not completely preclude propagule success (Catford et al. 2009). Propagules of non-native fouling species typically arrive in recipient communities via shipping or the other aforementioned vectors.

One biotic interaction commonly found in recipient benthic fouling communities is that of biotic resistance. Stachowicz et al. (1999) tested the influence of recipient 
fouling community diversity on the success of non-native fouling species propagules and found that communities with greater native diversity were less invasible, presumably due to less availability of primary space, an essential fouling resource, and temporal patterns of abundance (Stachowicz et al. 2002). These tests of fouling community resistance were conducted on experimental plates where diversity was manipulated (Stachowicz et al. 2002). Without manipulating diversity, artificial structures have also been shown to promote growth of non-native species (Tyrrell \& Byers 2007), but hard-substrate, benthic habitats where fouling species are also found often have greater instances of biotic resistance to invasion (Kimbro et al. 2013). Benthic biotic resistance typically occurs through consumption, and this resistance through consumption does not extend to suspended, artificial structures (Dumont et al. 2011a, 2011b, Simkanin et al. 2013, Forrest et al. 2013). Predation by native species can be an important interaction that limits the distributions of non-native species (Carlsson et al. 2009).

Although Stachowicz et al. $(1999,2002)$ test diversity and competitive interactions between fouling species, studies looking at the influence of the diversity of predators are lacking. Due to the recognition of non-native ascidians as a major problem in these systems (Lambert 2007), studying predator-prey interactions between suites of native predators and ascidians may help elucidate ecosystem function by determining the risk of invasion to different habitats like benthic versus suspended (artificial) structures. Looking at the interactions of non-native ascidians and incorporating them into niche community ecology theories about predation will further illuminate recipient community invasibility (Shea \& Chesson 2002). For example, various Platyhelminthes and 
Opisthobranch predators have been found to specialize on ascidians with chemical defenses in order to sequester those chemicals to use as defense for themselves (Millar 1971, Paul et al. 1990, Kubanek et al. 1995). It is unclear how such specializations play out in the context of a native ascidian versus a non-native ascidian. However, specialist predators evolve with native prey species making them unlikely to offer any resistance to non-natives. In fact, native predators may indirectly facilitate the growth of select ascidian species in the fouling community by depredating more palatable competitors (Nydam \& Stachowicz 2007). These indirect positive interactions may increase the risk of spread of non-native species and may be recognized by managers in order to monitor impacts. Therefore, in marine ecosystems, palatability characteristics of a marine nonnative species, or how attractive the species is as food, and the presence of specialist predators may be influencing the response of recipient communities, which, in turn, may limit or enhance abundance of the non-native species.

Characteristics of ascidians that fend off predators (defenses) have been of interest to marine biologists and ecologists as early as Millar (1971), who wrote that these species typically experience far less predation than neighboring fouling taxa. The toxicity of certain ascidians had been studied; however, it wasn't until Stoecker (1980a) that the ecological relevance of such toxicity was tested through feeding assays. Other defenses later evaluated through feeding assays include tunic structure or thickness and the presence of spicules (Chanas \& Pawlik 1995, Koplovitz \& McClintock 2011). These tests for the ecological significance of defense mechanisms are not generally conducted in the framework of invasions ecology. However, Lages et al. (2006) conducted 
chemical feeding assays assessing the defensive properties of a non-native species that threatened the coral reef of Arraial do Cabo, Brazil, showing that these studies may be used to assess the associated risks and impacts of particular invading species. If, for example, a species has a chemical defense (inorganic or organic; Pisut \& Pawlik 2002) that is effective against prominent enemies in the recipient habitat, there may be greater risk associated with that non-native species (Lages et al. 2006). Based on these palatability studies, however, it is clear that characteristic defenses against predation by one kind of predator may not be effective or may have limited efficacy against another (Tarjuelo et al. 2002, Koplovitz et al. 2009), indicating that the diversity of predators in recipient habitats may be important in determining invasibility.

My study is unique in that it aims to combine the concepts of invasiveness and invasibility through feeding assays and caloric content analyses, while determining the influence of a suite of predators. Although some work has been done using multiple predators in a native fouling species versus non-native context (Shinen et al. 2009), predator exclusion was conducted in one rocky shore habitat and laboratory preference tests were conducted for a system where the native species was significantly more successful than the non-native mussel. Here, I compare predators and ascidian prey, again in the native versus non-native context, but across two habitat types, one in which the non-native species may be considered successful. I identify a specialist predator of a native ascidian species, as well as a predator offering biotic resistance to Botrylloides violaceus. My results suggest that tunic thickness or structure could be an important characteristic indicating the potential invasiveness of ascidians. Although conducted at 
one site on the Oregon coast, it builds on existing predator defense literature by presenting a new experimental model that may be used to develop larger marine invasions studies with geographically comprehensive findings. Understanding these biotic interactions on the Oregon coast and the factors involved may ultimately be used as components in invasion risk models to be referenced by managers in the state, or ideally along the West Coast (Williams \& Grosholz 2008). Regardless, testing and characterizing biotic interactions adds to our understanding of the role predation plays (based on predator community composition and prey defenses) in shaping fouling communities on floating and nearby benthic habitats, and more broadly on the role of predation on invasion success in anthropogenic versus natural habitats.

Given the historical context of non-native fouling species issues, I have aimed to contribute to overall understanding and management of non-native fouling species. In coordination with managers and scientists, I have developed a Regional Biofouling Management Plan and I have conducted a study comparing predation rates on, and palatability characteristics of, native versus non-native ascidians. The Regional Biofouling Management Plan specifically aims to offer guidance to the states of Oregon and Washington in preventing and mitigating impacts of non-native fouling species, based on primary and gray literature and managers' input. My survey and experimental work aim to reveal how ascidian prey palatability characteristics interact, in a native versus non-native species context, with a suite of predators across benthic versus suspended structure habitats in Charleston Marina, Oregon. The chapters herein offer new information and structure regarding coordinated vector management at a regional 
level and a new understanding of the biotic interactions involved in non-native fouling species' success. 
Chapter 2: Pacific Regional Biofouling Management Plan
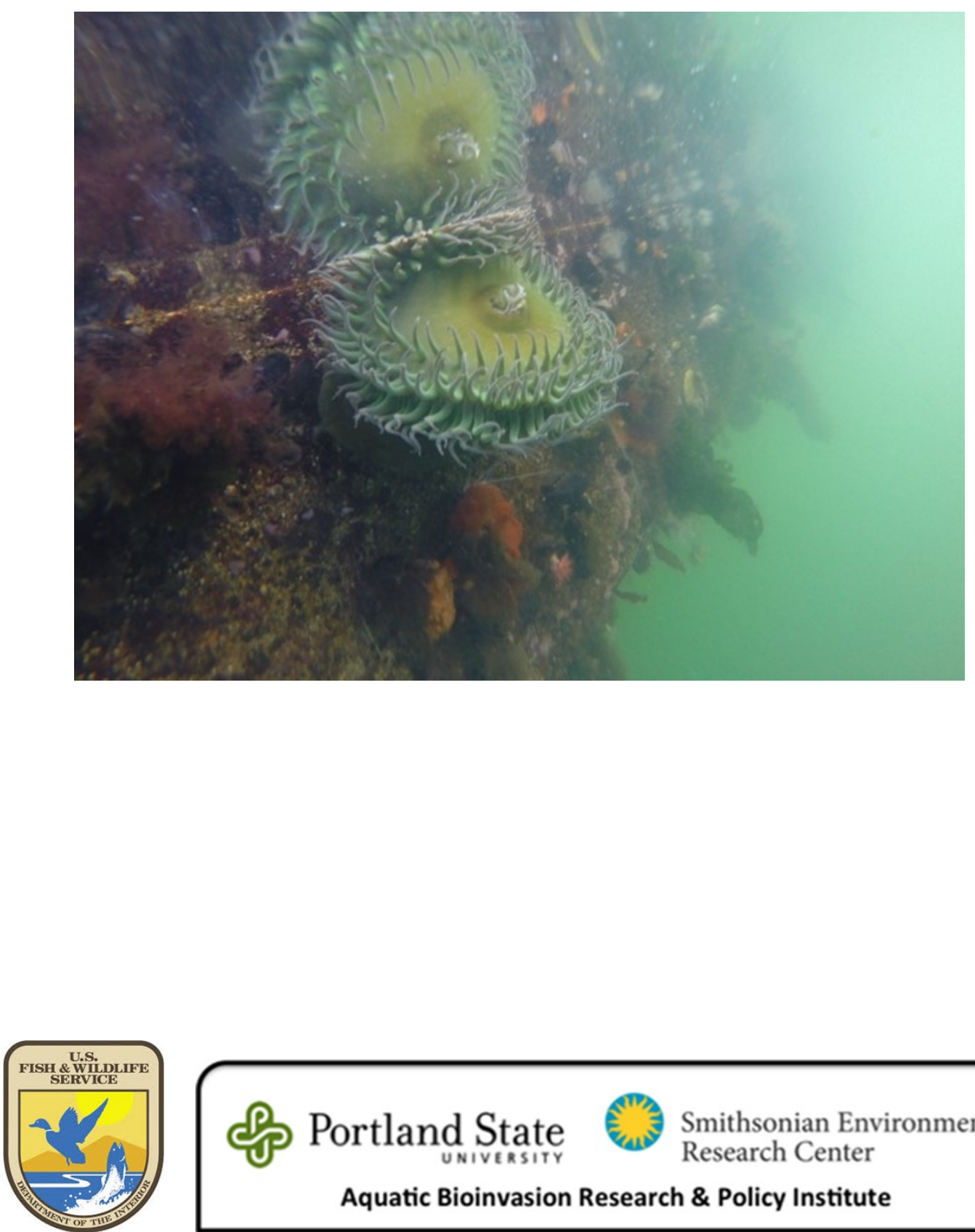

舟 Portland State

Smithsonian Environmental Research Center

Aquatic Bioinvasion Research \& Policy Institute 


\section{Introduction}

Non-native species, once established, have the potential to cause severe environmental and economic damage in marine systems (Bax et al. 2003).

Environmental threats include the spread of voracious predators like the European green crab (Carcinus maenas), the spread of harmful algal blooms by filter feeders (Rosa et al. 2013), and the spread of colonial foulers that overgrow native seaweeds, seagrasses, and bivalves (Valentine et al. 2007). Invading marine non-native species also have a significant impact on aquaculture operations, particularly fouling species that damage equipment and stock species (Aldred \& Clare 2013). The impacts associated with marine invasive species are projected to worsen as waters warm and globalization increases along with vector-associated risks (Occhipinti-Ambrogi 2007). In fact, the total number of reported marine non-native species has been increasing over the last 200 years, especially in recent decades (Ruiz et al. 2000, Bax et al. 2003). However, several factors complicate site- and species-specific management efforts. First, coastal biological communities have few documented historical baselines from which to determine the original range of species (Carlton et al. 1999). Second, many non-native species are established in ports and harbors throughout the West Coast of North America (Fofonoff et al. 2003b). In addition, multiple non-native species may be transported simultaneously by several, often unregulated vectors in a multi-jurisdictional marine environment (Bax et al. 2003). The anthropogenic structures of harbors host high numbers of non-native species, and although these species do not always infiltrate native habitats, their dominance in harbors serves as a propagule supply threatening to infest natural substrata, 
and negatively impact coastal ecosystems (Clark \& Johnston 2009). In order to address the threat of non-native marine species, policies regulating ballast water exchange have been enacted at the national and state levels. However, little else has been done to address other marine vectors, including hull fouling and the aquaria trade. The former is only provisionally addressed through ballast water regulations (Davidson et al. 2012).

\section{Regional Approach}

A regional approach to the management and prevention of spread of non-native species reduces the number of weak links in cross-jurisdictional policies (Peters \& Lodge 2009). The marine environment offers a number of challenges to management of nonnative species, challenges that make a regional approach even more important. First, infested areas are connected, along the coasts of a region by currents as well as anthropogenic movement (Wasson et al. 2001, Ruiz et al. 2011). Although non-native marine species management may be occurring in one jurisdiction, the success of such efforts is strongly limited by the scope, scale, and timing of management actions of neighboring states (Peters \& Lodge 2009). Second, these habitats are difficult to monitor because of their often reduced accessibility, especially in areas like British Columbia and Alaska and subtidal habitats. Similarly, third, implementing management strategies often requires solutions unique to the aquatic, tidal environment. Fourth, marine species can often be difficult to identify, potentially delaying response actions when a non-native species is detected. Moreover, federal and some state agencies often do not have clear authority in the marine environment as many of these agencies were developed to address issues in forestry and agriculture. Regional agencies may work with local and state 
agencies to define clear lines of authority, going before state legislatures to address missing legal authority. Regional collaboration increases coordination in addressing these challenges by developing contacts and a larger support system. This collaboration broadens the pool of available expertise for detecting and mitigating the impacts of nonnative species. Coordinated regional management may reduce the risk posed by marine vectors that operate across jurisdictional lines. Temporary or sporadic pathways may be addressed regionally, as needed by a team of experts representing multiple levels of jurisdictions (i.e., tsunami debris, events such as America's Cup, or economic recession). Coordinated response actions may also be more effective at limiting or stopping the stepping stone spread of nuisance species via busy transport hubs along the coast (Floerl et al. 2009).

\section{Community Approach}

Non-native fouling species are a serious threat to native communities as only the hardiest individuals or colonies may survive long, international transport, increasing the likelihood of successfully establishing in recipient habitats, outcompeting native counterparts, and furthering spread to neighboring habitats through smaller scale transport mechanisms. Fouling communities harbor a high percentage of non-native species, especially on anthropogenic structures. These sessile organisms attach to hard substrate such as rocky benthos, rip rap, docks, or boat hulls. Fouling species have similar ecological functions and life histories. They are primarily sessile, multicellular, and often easily accessible and readily identifiable organisms, making them a good model for community-level management of non-native species. This community includes a 
range of taxa: tunicates, bryozoans, hydrozoans, barnacles, anemones, mussels, sponges, and algae, with over 60 key non-native species along the Washington and Oregon coasts (Fofonoff et al. 2003b). Most life stages of fouling species have a limited dispersal potential, although fouling communities may also harbor mobile non-native organisms (e.g., amphipods, crabs). By managing at a community level, all of these taxa are concurrently targeted. These species can become of particular concern for the aquaculture industry, but are also a nuisance for maintenance of marina infrastructure. In aquaculture facilities, non-native fouling organisms, such as the colonial tunicate Didemnum vexillum, can kill product species and cause severe economic damage (DFO 2013). Invasive fouling species may also threaten native ocean-floor biota once established in rocky benthic habitat (Lengyel et al. 2009). Although many non-native tunicate species and other fouling organisms appear limited to suspended anthropogenic structures, the danger lies in the build-up of a propagule supply of non-native species and potential spread of that supply to novel areas (Clark \& Johnston 2009). Occasionally, propagule supply becomes large enough to overcome a threshold or a disturbance causes shifts in natural community structure that may allow non-native species the opportunity to establish in benthic habitat (Clark \& Johnston 2009). This highlights the importance of limiting propagule supply within the community to prevent successful establishment of marine non-native species in natural habitats. In general, successful non-native species are able to adapt easily to disturbed or polluted environments, making high-traffic harbors hotspots and sources of fouling marine non-native species establishment (Zabin et al. 2014). A community approach to managing fouling species establishes a focus on vectors, simultaneously reducing the spread and impacts of multiple organisms 


\section{and providing greater flexibility for responding to future invasions than a species- specific approach.}

\section{Vectors}

The regional management and ecological community perspectives may be applied to a suite of marine non-native species vectors. Shipping has been identified as the main transoceanic transfer mechanism of non-native marine species (Ruiz et al. 2000). However, only one aspect of the industry is regulated (ballast water) with brief provisional mention of hull fouling maintenance for commercial vessels. There is no single vector responsible for the spread of marine fouling organisms. For San Francisco Bay, hull fouling as a vector contributed as many marine non-native species as ballast water (Bax et al. 2003), indicating the need for broader management. Bax et al. (2003) lists eight non-native marine fouling vectors: commercial shipping, aquaculture and fisheries, drilling platforms, canals, aquarium industry, recreational boating, dive practices, and floating debris. Most of these are pertinent to the fouling community and may be responsible for regional transport of fouling organisms. Although technological advances in shipping speed have reduced fouling in some cases, hull fouling is common on small and slower vessels (Bax et al. 2003, Zabin et al. 2014). Assessments of small boating movements and operations are lacking (Davidson et al. 2012). Fouling species may also be spread through the movement and trade of docks and other infrastructure, including aquaculture equipment. Examples of non-native aquatic species management that address multiple vectors include the Biosecurity Plan for the Shetland Islands, which addresses marine non-native species broadly (Collin et al. 2015), the freshwater 
Dreissenid mussel rapid response plans (Draheim et al. 2013, DeBruyckere et al. 2014), and Aquatic Nuisance Species state plans (Meacham 2001). The prevention, early detection, rapid response, and control practices described in these plans may assist in informing the management of multiple fouling vectors across Washington and Oregon coastlines.

Current infestations and any ongoing management efforts addressing them may point out any existing gaps in the management approaches to non-native fouling species at local, state, and regional scales. An example of a marine non-native species instigating response efforts that span a variety of localities is Didemnum vexillum. This non-native colonial tunicate was first detected on the West Coast of North America in San Francisco in 1993 (Fofonoff et al. 2003b). This nuisance species has subsequently spread to Puget Sound, Winchester and Coos Bays, and Sitka, Alaska (Fofonoff et al. 2003b). Considered a serious threat to aquaculture and fisheries, D. vexillum carpets hard substrate, docks, and infrastructure in some cases diminishing abundances of other fouling organisms in benthic habitats (Lengyel et al. 2009; Bullard et al. 2007). Infestations on the West Coast of North America have garnered management concern, making $D$. vexillum a good rallying point for managers to begin coordinated plans to prevent spread and to diminish existing populations of non-native fouling species. This is an example where a regional plan may help prevent spread, help local control efforts by reducing reintroduction risk, allow for the prioritization of management goals, and also help manage additional non-native species. 
Existing management efforts and plans covering different geographical scales may be used to inform regional efforts of biofouling management. A state-level example of multi-species management is Washington's Aquatic Nuisance Species plan (Meacham 2001) that addresses multiple freshwater species and pools networks and expertise across the state. Few coordinated regional efforts have been made in the U.S. to address nonnative species. Regional management models include the West Coast Governor's Agreement Spartina Eradication Work Plan (WCGA 2010), addressing existing incursions, the $100^{\text {th }}$ Meridian Initiative (Mangin 2011), limiting westward spread of zebra/quagga mussels, and the Regional Biosecurity Plan for Micronesia \& Hawaii (Ruiz et al. 2014), addressing risks of incursion for multiple species. The Marine Biosecurity Regional Plan for Micronesia (Ruiz et al. 2014) uses the conceptual framework from Ruiz \& Carlton (2003) to provide recommendations for vector analysis, vector disruption (regulations or requirements), and evaluation of the efficacy of these disruptions for a range of vectors operating in the region. The plan recommends the development of hull cleaning regulations to reduce the threat of non-native species (Ruiz et al. 2014). The aforementioned examples all address aquatic non-native species, although terrestrial examples of regional management, such as the Emerald Ash Borer Program, may provide insight into multi-state coordination as well (USDA-APHIS 2015).

Challenges in West Coast state-level management of hull fouling include authority gaps and knowledge gaps about specific vector risks. The state of California has moved beyond this in regulating the commercial shipping vector, by requiring annual reporting of hull cleaning practices (Takata et al.2006). A hull cleaning standard for this 
vector, however, has not yet been established. Another issue in California is the lack of a specific management entity to address recreational and fishing vessel operations. Despite this gap in authority, Oregon and Washington often look to California in terms of regulation efforts, similar to ballast water, and each of these states have built momentum to address biofouling and non-native fouling species. Both states have published biofouling vector reports and review existing regulatory frameworks regarding biofouling management in the state, although Oregon's report is focused on shipping traffic (Davidson et al. 2014, Paul 2011).

This Regional Biofouling Management Plan has been developed to address the need for coordinated and comprehensive management of fouling species across states. Gaps in response activities of multiple jurisdictions lead to windows of opportunity for the spread of high risk non-native marine species. Cooperation between regional jurisdictions is needed for effective management of non-native fouling species (Bax et al. 2003). Managing vectors of spread at small and large scales enacts prevention activities that may be effective against unknown threats and will bolster control efforts targeting established non-native marine species (Ruiz \& Carlton 2003). In this case, managing fouling vectors and infestations at the regional level provides multiple jurisdictions with lines of communication which may increase prevention opportunities as well as offer a foundation for managing other fouling invaders, increase understanding of regional vector activities, and enhance knowledge of available response options. Though this plan focuses on the states of Washington and Oregon, it aims to inform broader, coast-wide efforts and to be expanded and modified over time by managers and other stakeholders. 


\section{Vectors}

The following vectors pose a threat to marine infrastructure and native coastal ecosystems by transporting non-native fouling species as well as alien non-sessile species associated with the fouling community.

\section{Shipping}

Not all commercial vessels have a uniform impact as vectors of non-native species. Containerships, for example, may have less of an impact as they port for short durations and travel at high speeds, sloughing off most fouling organisms save for a few niche areas (Davidson et al. 2009). This may not be the case for other kinds of vessels. In fact, the frequency of vessel types and vessel routes are important predictors of propagule supply to recipient ports (Verling et al. 2005). Fofonoff et al. (2003a) used 316 species from the NEMESIS database to determine likely vectors of those species. Only 65 of 316 could not be attributed to shipping, and 60 of the species spread via shipping are attributed to hull-fouling alone (Fofonoff et al. 2003a). Although vessel hulls may not appear fouled, other niche areas, like sea chests, provide the risk of spreading successfully transported non-native species (Fofonoff et al. 2003a). The route or source region as well as the destination of the vessel are also important factors in characterizing the risk of invasion. Source regions determine what characteristics an invading species has that may allow it to establish successfully in a recipient region (Miller \& Ruiz 2009). For example, a broad species range generally indicates a species' 
ability to tolerate a wide range of environmental conditions. Though shipping is broadly the most impactful vector of non-native marine species, many factors may define the level of risk presented by an individual vessel.

\section{Commercial Vessel Hulls:}

Marine organisms foul submerged surfaces of commercial vessels stopped in ports. These surfaces include hulls, sea chests, and anchor systems. Fouling organisms create drag while attached to vessel hulls. Vessels that travel to high risk areas may accumulate non-native species and spread them to other vessels, port areas, and surrounding natural areas (Davidson et al. 2014, Sylvester et al. 2011). In some areas, a greater number of non-native species may have been introduced through hull fouling than ballast water (Ruiz et al. 2015).

Ballast Water:

Ballast water is the water taken in by vessels for balance. It is particularly important for large commercial ships, but can apply to any size vessel. Water that is taken up from one port and then released in another can introduce new species into an area (State of Alaska 2015). While it can also take up other functional groups, ballast water can take up fouling organisms in their planktonic stages and deposit them in new areas (Davidson et al. 2014). This is an important vector for fouling organisms because it can transport a high number of individuals per species as well as many species in the 
larval stage, increasing the likelihood of survival in the recipient area and introduction of species or genotypes new to a recipient port.

\section{Recreational Boating:}

Recreational boating provides a high risk vector for the spread of non-native fouling species (Davidson et al. 2010, Darbyson et al. 2009). Fouling species can attach themselves to the hull of the boat, anchors, lines, boat bumpers, and other gear. Recreational vessels are generally in one location for prolonged periods of time which lends itself well for the development of fouling communities. When they do move around, recreational vessels can visit sheltered and shallow harbors that commercial vessels would not be able to access. Recreational boats are also likely to be transported over land and can potentially introduce species across terrestrial barriers. Darbyson et al. (2009) found recreational boats to be a greater risk than commercial fishing boats, as recreational boats are often docked outside their home harbor, whereas commercial fishing boats return to the home harbor every night in the Gulf of St. Lawrence, Prince Edward Island.

\section{Commercial Fishing:}

Hulls and fishing equipment used by the commercial fishing operations can be a source of biofouling spread. Equipment may be frequently sold and traded to new areas, simultaneously transporting non-native marine species. Although operations are 
stochastic, this vector may be an important risk in the spread of marine non-native species (Darbyson et al. 2009, Bax et al. 2003).

Aquaculture Infrastructure:

The movement of aquaculture products was responsible, historically, for introducing many invasive species (Davidson et al. 2014). While current aquaculture practices have greatly reduced the number of species being introduced, aquaculture infrastructure still provides a potential vector for fouling organisms through the movement of fouled equipment, such as product cages, from one place to another.

\section{Bait shipments/seafood:}

When both seafood and bait are packed for shipment, they are often packed in seaweed. The seaweed itself may be a non-native species, but can also harbor additional organisms than the intended shipment and, when dumped by the receiver, can introduce new species into the environment (Davidson et al. 2014, State of Alaska 2015). This is a relatively low-risk vector for fouling organisms because many of them don't attach to seaweed as a primary substrate, although hydroids may be associated with these aquatic plants (Davidson et al. 2014). Non-native bivalves may be a significant risk stemming from the seafood industry transporting new species (Chapman et al. 2003). 
Aquarium Trade:

Because aquarium keeping is an extremely popular hobby, it is a very lucrative and well-represented vector for marine non-native species and potentially problematic as up to one-third of the most dangerous aquatic invasive species have been introduced via aquaria (Williams et al. 2012). In the Pacific Northwest, an estimated 2,500 fish species are released annually into fresh and marine waters (Strecker et al. 2011). Aquaria stores carry about 124 aquatic plant species, many of these, as well as released fish species, have the physiological potential to survive in Pacific Northwest waters and establish populations (Strecker et al. 2011). Though fouling species may not be directly sought after in the aquarium trade, it is possible that they could be transported as hitchhikers with the desired species and then discarded in the environment. Introductions from the aquarium trade are relatively low compared to some of the other vectors (shipping, boating, aquaculture), but the trade is growing extremely quickly and could become far more problematic in the future.

Ocean Currents (small scale)/ Marine Debris:

Fouling organism larvae may be transported regionally by ocean currents. Larval survival periods for species of concern should be considered when mapping areas of likely spread by this vector. Marine debris as a vector of non-native fouling species has been of recent concern with the arrival of tsunami debris on the West Coast. Debris or 
plastics in the ocean may carry non-native macro and micro-organisms to new habitats and may remain in the ocean for hundreds to thousands of years (Barnes et al. 2009).

\section{Assessment of Vector Operations in the Region}

Vector operations have been assessed in Puget Sound, WA (Davidson et al. 2014), including commercial vessels, fishing vessels, recreational boats, live bait, aquaria, aquaculture, marine debris, and live seafood trade. A recreational boater survey and interviews were conducted in Puget Sound with 150 responses/interviews; results are provided in section two of Davidson et al. (2014).

The same boater behavior survey conducted in Washington was briefly attempted in Charleston Marina, Oregon in the late fall of 2015, to gain a better understanding of recreational boater travel and cleaning practices. Response was very low, despite the incentive chance to win a $\$ 200$ gift card for Englund Marine. Future attempts to quantify boater practices will likely require a stronger presence in study marinas to promote the survey. This initial survey for Charleston Marina, OR may have, at least, introduced Portland State University and the Smithsonian Environmental Research Center to the community, laying groundwork for further survey efforts. A comprehensive report assessing the multitude of vectors in Oregon is needed.

Oregon Boater Survey Results 
A low survey response rate $(n=8)$ prevents quantitative analysis, but what follows is a description of responses. To refer to questions asked in the survey see Appendix A. The travel and cleaning practices of four fishing boats, three sailboats, and one recreational motorboat are described through responses. The most frequently listed home harbor was Charleston Marina, OR, with one respondent listing Newport, OR and another claiming no home harbor as the one recreational motorboat is kept inland for 9 months of the year. Half of the respondents' boats had been hauled out for anti-fouling paint application within 2015: one fishing boat in 2014, one sailboat in 2013, one fishing boat had not applied paint to an aluminum hull since 2006, and the recreational motorboat does not have anti-fouling paint on an aluminum hull but is frequently cleaned out of water (maximum time in water is 2 weeks). Of the anti-fouling paint manufacturers named, two were Pettit, one was $\mathrm{ABC}$ 3, and one was Trilux. If the boat had been cleaned since application of anti-fouling paint, the most common method was out of water, with one sailboat respondent writing in pressure washing out of water at the marina. One sailboat respondent claimed underwater pressure washing was conducted once per year, though the date of most recent anti-fouling paint application was 2013. The length of time a boat was claimed to have been stationary, in-water ranged from one week to 6 months, with an extreme of two years for a sailboat.

Cleaning practices were compared to the number and kind of trips made by each boat. The number of trips made since the last anti-fouling paint application ranged from 0-10 for sailboats and 1-145 for fishing boats. One fishing boat made 200 local trips with no overnight stays in the last 12 months, but claims annual cleaning practices and a recent 
(2015) application of anti-fouling paint. Sailboat local trips in the last year ranged from $0-10$. The sailboat that made no trips in the last year has been stationary for 2 years, with no cleanings since its 2006 application of anti-fouling paint. The other two sailboats claim annual cleaning. Fishing boat local trips over the last year range from 30-200. One fishing boat, with a recent (2015) anti-fouling paint application and cleaning, claimed 7 trips that included overnight stays at two other marinas, one was Newport, OR (3 trips) and the other was Fort Bragg, CA (4 trips). The Newport fishing boat made trips to other marinas in Oregon that included at least 20 overnight stays at Charleston and Garibaldi, OR.

In general, there is a greater amount of variation in cleaning practices amongst the sailboats and recreational motorboat compared to fishing boats. Of the three sailboat owner respondents, one owns a sailboat that posed a risk for transporting fouling species due to its long stationary periods and lack of regular cleanings since 2006. The recreational motorboat does not pose a significant threat to marine environments as all of its trips are local and the boat was stored out of water or used in freshwaters for 9 months of the year. All fishing boats claimed at least an annual cleaning. The four fishing boats each had an anti-fouling paint application since October 2014. Though fishing boats traveled more frequently and farther than the sailboats and recreational motorboat, their cleaning and paint application practices were regular. This qualitative analysis should be followed by further survey efforts to quantitatively assess the recreational boat and fishing vectors in Oregon. 


\section{Biofouling Management Framework}

The intent of this management framework is to enhance coordination and comprehensive management of non-native fouling species across states by assisting dialogue between agencies and other management entities. The recommendations herein are extracted from science-based and management-focused literature and plans and their purpose is to provide general guidance. Ultimately, managers must decide which actions are feasible in coordination with other jurisdictions, although preventative management efforts should be the priority (Leung et al. 2002, Finnoff et al. 2007). This framework should not be viewed as a step-by-step guide, but rather as goals to be achieved or modified through prioritization and a pooling of regional resources and expertise.

Issue: No multi-state biofouling-specific management group currently exists.

Recommendation: Identify potential members to form a biofouling specific group whose purpose is to coordinate input from all stakeholders and generate management and policy suggestions. Provide recommendations to the West Coast Governor's Agreement (WCGA) or to the states of Oregon and Washington to appoint a biofouling specific action team or committee, similar to the Tunicate Response Advisory Committee (TRAC) for Washington tunicate management (Pleus et al. 2008) or Spartina Action Coordination Team for the multi-state Spartina management plan (WCGA 2010). This group may be responsible for the instigation or development of more specific 
management plans as needed and may also convene to provide recommendations to legislative and management entities and attract funding.

Issue: Scientific expertise will be needed in each management phase addressing fouling organisms.

Recommendation: Provide recommendations to WCGA or the states of Oregon and Washington to appoint a scientific advisory team on biofouling. Expertise will be used for taxonomic issues and action recommendations. The scientific advisory team should also have trained divers with a strong understanding of invasions ecology to conduct diver transect surveys.

Prevention

Issue: No hull husbandry program for commercial vessels is currently in effect.

Recommendation: Work in partnership with commercial vessel groups to create a hull husbandry program for ocean going commercial vessels that is similar to California's program. 
Task A: Implement a hull fouling reporting form identical to the California hullhusbandry annual reporting form to enhance cooperation along the coast. Hull fouling data may be collected annually.

Task B: Implement regulations, like California, that require adequate hull cleaning in accordance with best biofouling management practices that utilize latest technologies and protocols, with cleaning to occur before:

- the Safety Construction Certificate expiration data

- the USCG Certificate of Inspection expiration date

- 60 months since last dry docking

Task C: Inspect hulls upon boarding and issue citations similar to those concerned with ballast water and issue delinquent notices as needed.

Issue: The spread of non-native fouling species via recreational vessels within the region is not currently subject to regulation. The scope of this vector needs to be determined as data are rarely collected on the movement of recreational vessels in and around the region.

Recommendation: Limit spread of non-native fouling species via recreational vessels within the region. This could be done by building on to recreational vessel programs 
already in place like the Oregon State Marine Board's Clean Marina Program (State of Oregon 2014) and Clean Marina Partnership in WA (Clean Marina Partnership 2014) or by having major marinas implement policies similar to Darwin, Northern Territory, Australia (Northern Territory Government 2014).

Task $A$ : Require incoming vessels to complete a questionnaire about movements and cleaning practices upon entry, in-water inspection may be necessary depending on response.

Task B: Require or promote clean-drain-dry for vessels removed from water.

Task C: Require decontamination for vessels coming from waters with known, high-risk pests.

Task D: Require anti-fouling paint to be kept in good condition.

Task E: Work in partnership with recreational vessel groups and marina operators to develop and maintain better records of recreational vessel movement patterns and cleaning practices within the region that can be accessed for research and risk assessment purposes. 
Issue: Import permits are not required for all non-native species being shipped into the region, although international shipping does require labeling, for live bait, aquaria trade, live seafood, and aquaculture industries. Internet orders are difficult to track and can be used to circumvent the permit process. Each state and national permitting rules differ, and these gaps need to be addressed.

Recommendation: Work in partnership with live bait, aquaria trade, live seafood, and aquaculture industry leaders (approaching interest or lobby groups) to address risks.

Task A: Require health certifications for live bait species and consider banning the use of seaweed as packing material for shipments of both live bait and live seafood.

Task B: Work with an academic partner to survey which species are available for sale as aquaria species in the area both through retail outlets and hobbyist groups, and use climate matching and distribution modeling to determine whether these organisms could survive in local waters (Holcombe et al. 2010, Kulhanek et al. 2011). A fouling community specific example of non-native species modeling is provided by Herborg et al. (2009).

Task C: Update state prohibited species lists accordingly, or work to streamline efforts to add or remove prohibited species. Promote the Don't Let It Loose 
campaign, developed and disseminated by the U.S. Fish and Wildlife Service, throughout the region.

Task D: Standardize interstate import permits for all marine species and expand the permits to include home aquaria trade and all aquaculture species and gear. The expanded permit program could be overseen by one agency per state such as WDFW for Washington.

Task E: Develop use of a web crawler similar to that used by U.S. Department of Agriculture to track and regulate internet orders. The Great Lakes Commission has developed a web crawler that may become available for national use and could potentially incorporate marine species (Great Lakes Commission 2014).

Issue: Public knowledge and concern for fouling issues may be lacking.

Recommendation: Develop an outreach plan about the impacts of fouling and nonnative species with a target audience of boat owners, marinas, aquaculturists, and diving clubs.

Task A: Convene the Biofouling Action Team to determine agency or university partner responsible for developing outreach materials. 
Task B: Develop materials that encourage cleaning, draining, and drying of aquatic equipment and boats highlighting the fact that fouling creates drag, increasing fuel costs for boats, and may suffocate aquaculture products. General information and pictures of non-native species of concern and their potential impacts to native environments should also be provided.

Task C: Distribute outreach flyers, posters, or digital media to diving clubs, marinas, recreational boating clubs, aquaculturists, and any other relevant parties.

Early Detection

Issue: In order to increase chances of detecting new threats, managers and agencies active in relevant habitats need taxonomic information on native and non-native fouling species as well as current species range maps stating which species are established and which areas are currently being managed.

Recommendation: The Biofouling Action Team may take on responsibility or delegate the production and distribution of a Marine Fouling Species Identification Guide for fouling organisms for California through Alaska, similar to the Marine Invasive Species Identification Guide for the Puget Sound Area (Eissinger 2009). Ideally, agencies and/or university partners with existing outreach infrastructure in marinas, dive shops, and 
aquaculture facilities will take on responsibility for the identification guide. Build onto existing guides (e.g. Eissinger 2009, Oregon Sea Grant 2013).

Task A: Include summary information about the species, a brief description, size, color, habitat, tidal height, salinity, temperature, and any similar native species. Also include a picture of the species and appropriate instructions for reporting. All information must be verified by scientific advising experts.

Task B: Compose a list of taxonomic experts and where voucher specimens are located, including a description of their accessibility. This is an important reference for verifying the presence of non-native species.

Task $C$ : Distribute guide to managers and any other relevant parties, such as passive detection networks (organizations or individuals who detect invasions while conducting other activities).

Task D: Provide clear resources describing to whom managers and passive detection networks can report non-native species sightings to and publicize reporting to a particular hotline or agency.

Task E: Encourage and facilitate reporting and detection opportunities of potential invasions by developing citizen science opportunities, such as a BioBlitz event 
(National Geographic Society 2014), and encourage the distribution of identification guides by existing outreach programs.

Task F: Promote and review the viability of new technological advances and applications in invasive species detection in aquatic environments, such as environmental DNA assessment (Darling \& Mahon 2011, Jerde et al. 2011).

\section{Survey/Monitoring}

Issue: There is a lack of fouling species baseline data along the Washington and Oregon coasts.

Recommendation: Coordinate a region-wide mapping effort to document the distributions of and invasion risks from non-native fouling species. This can be used as a source of baseline data upon which the detection of novel non-native species may be based as well as detection of changes in density or the impacts of a present species. Existing data can be compiled in coordination with academic researchers into a GIS database.

Task A: Classify presence/absence of non-native fouling species in target coastal bays and harbors. Sampling sites should be chosen based on vector activity. 
Task B: Assess and compare vector activities to known distribution data. If information is lacking in any sites found to be at risk due to vector activity, these sites should be identified and addressed (Ruiz et al. 2015).

Task C: Survey key sites affected by vector activity that either have not been sampled or have not been sampled for all necessary information. This survey may operate as a BioBlitz event to be held to sample multiple sites quickly (National Geographic Society 2014). This may be an opportunity to engage community volunteers to help in initial sampling while simultaneously conducting outreach about non-native fouling species to volunteers.

Task D: Define areas of high-risk in the region based on survey data and vector assessments. These areas will be targeted for future monitoring efforts. As vector activity shifts, increasing risk in new areas or decreasing risk in target areas, these high-risk locations will need to be re-designated.

Issue: Fouling communities frequently shift and change due to climatic conditions and a high influx of novel species from shipping and other aquatic activities, yet no large-scale, long-term monitoring of coastal systems is active in the region. 
Recommendation: Monitor marinas and ports using dive surveys and stakeholder questionnaires, and where possible monitor aquaculture infrastructure (Murray et al. 2013).

Task A: Create an active detection network comprised of trained divers and agency workers as well as members of the scientific advisory team with taxonomic expertise. Agencies may coordinate dive surveys and taxonomic experts may be consulted to identify species. Members will devote part of their time to finding non-native species, focusing on species of concern, high-risk pathways, high-risk locations and stationary structures in these locations.

Task B: Conduct biannual (late spring/early summer and mid-winter) dive surveys of areas of high risk and document any changes from the known baseline data. If available, a remotely operated underwater vehicle (ROV) may also be used to help conduct the survey. Dive surveys can be conducted using diver transects along which the diver documents any non-native species present. Scoping and detection requires an understanding of invasions ecology.

Task $C$ : Include hull surveys of recreational boats, if there are any present in the area of risk, to determine a possible difference in species between natural and artificial substrate. Hull dive surveys can be conducted using photographs of the submerged surfaces, documentation of all non-indigenous species present, and 
sampling of any species with uncertain identification to be brought into a laboratory.

Task D: Utilize the behavioral questionnaire in Appendix A to send to members of marinas, aquaculturists, recreational boating clubs, and any other operators of potential vectors of non-native fouling species.

Issue: The interactions between non-native fouling species and other parameters, such as climatic conditions, are not well known.

Recommendation: Conduct research, working with academic partners, on climatic conditions and ecosystem disturbance patterns.

Task A: Conduct a literature review of existing knowledge on the relationship between climatic conditions and invasions in the fouling community.

Task B: Conduct research on specific tolerances of fouling community species to be used in distribution models that account for shifting climatic conditions. Projections may be used to inform management decisions. This is particularly important when the place of origin for the invader is known so it can be determined if the climate is similar, or will be similar enough for the invader to establish. In general, non-native species will be more resilient in the face of a 
changing climate, and some work has shown that this is true of fouling species (Sorte et al. 2010).

Rapid Response

Issue: Rapid response is often limited by a lack of coordination and a misunderstanding of jurisdictions.

Recommendation: Utilize Incident Command System (ICS) to compose hierarchy of responsibility for incursion response.

Task A: Convene the Biofouling Action Team to determine if ICS is the preferred management coordination tool. Lead agencies responsible for ICS may be identified according to geographic location and habitat type.

Task B: Agency responsible for Incident Command should host a training session for managers to become familiar with ICS prior to further fouling incursions.

Overall structure and responsibilities supporting ICS lead may also be determined. Trainings will ensure manager familiarity with their responsibilities in the midst of a rapid response event. 
Task C: Determine the criteria and process for coast-wide emergency protocols. Emergency declaration is often a tool to get past jurisdictional and authority issues. Protocols should be used to determine what is needed and when it is necessary to declare an emergency situation.

Task D: Conduct periodic (annual) table-top drills/exercises to train and test the ICS rapid response system.

Issue: Action options for rapid response, the prioritization of actions, and the response network and work flow need to be determined.

Recommendation: Create a rapid response framework and as new threats arise conduct a rapid assessment for detected or anticipated non-native fouling species.

Task A: Develop general frameworks and protocols addressing several taxa or a particular habitat that may later be used to guide species specific actions as novel non-native species are detected. The response to Caulerpa taxifolia in California may be used as a model of local response (Anderson 2005).

Task B: Convene the Biofouling Action Team and include the scientific advisory team to consult as a practice run of the framework is conducted by lead agencies. 
Task C: Convene the Biofouling Action Team and include a team of scientific advisors to consult. Using the collective knowledge of the BAT and the scientific advisors, develop species-specific rapid response plans that will be well coordinated between states.

Task $D$ : Respond rapidly to new incursions, as needed.

Issue: Initial detection may not locate the full extent of infestation.

Recommendation: Establish a network of trained divers and taxonomists to respond quickly when a new infestation is detected and to locate all proximal infestations and determine the extent of colonization or spread.

Task A: Coordinate with the scientific advisors team to assist with identification of organisms. Team members should have some overlap with members of the regional biofouling action team.

Task B: Develop protocol for emergency search of infestations and isolated colonies or organisms. 
Task $C$ : Establish emergency team of divers to act quickly in locating all proximal infestations to scope the extent of infestations. Divers will need to be trained in identification of the target species.

Issue: The infested area has the potential to allow further spread if no removal occurs or vector operations remain the same.

Recommendation: Inspect and clean all potential vectors and product leaving infested areas, especially if the non-native species is determined to be high risk by scientific advisors.

Task $A$ : Identify local operations and mechanisms that offer greatest risk for spread of the organism.

Task B: Begin inspections and cleaning of proximal infrastructure and vessels immediately following detection in order to prevent further spread to nearby locations. If further infestation is discovered beyond initial detection, expand vector inspection area to include newly discovered infestation sites.

Task C: Limit vessel or aquaculture operations, in extreme cases, should an invested agency have such authority. If no agencies have been given this 
authority Incident Command System may be implemented, or selected agencies will seek this authority from the state legislatures.

Issue: Permits and permissions will be needed to perform chemical and mechanical methods of removal.

Recommendation: Anticipate permits and permissions that may be needed in an incursion event, especially in hotspot areas where invasion is most likely to occur, while practicing ICS and rapid response framework exercises.

Task A: Infestations do not always occur on public property. It will be important to work with private ownership to coordinate removal. Develop or adopt protocol for approaching and working with private property owners.

Task B: Generate a list of possible treatments for different fouling organisms including all latest technologies. A chart of potential control/treatment options is included in the subsequent framework section.

Task C: Pesticide and other chemical applications must meet terms and timelines of state CWA/NPDES pesticide general permit and FIFRA label directions and restrictions. Any action funded or executed by federal agencies must adhere to 
NEPA regulations. Removal methods should be evaluated based on permitting terms, if available, to prepare for a detection event.

Task $D$ : Identify which treatments would be useful for which organisms and habitats and which extents of invasion.

Task E: Determine which permits would be needed for these treatments and to which agencies the permits must be submitted, such as Washington Department of Ecology and Oregon Department of Environmental Quality.

Task F: Agencies involved with the Incident Command System's planning branch should have permit applications organized and prepared in advance. Establish avenues for quick or emergency acceptance of permit applications.

Issue: Funding sources for invasive species control and eradication are lacking.

Recommendation: Develop and maintain a list of relevant funding sources. Although state Invasive Species Councils administer invasive species emergency funds, these are considered seed funds to initiate response and do not support a full response or eradication program. A list of potential funding sources and contacts will need to be developed. 


\section{Control}

Issue: Specific control options need to be assessed to inform decision-making.

Recommendation: Expand on existing knowledge as control methods are applied to new situations and identify knowledge gaps on control efficacy. Washington tunicate management control methods may be assessed broadly for the fouling community (Pleus et al. 2008). Chart of control options is provided as Appendix B.

Issue: No official decision matrix exists to determine which control methods may be most effective in mitigating the impacts and spread of established populations.

Recommendation: Develop a decision matrix to determine the appropriate control method for a specific species based on location of infestation, size, seasonal growth, species status, and the surrounding environment.

Task A: Convene to discuss when and where specific control methods may be the most effective. 
Task B: Compose a flow chart of questions to determine the extent and location of infestation, seasonal reproduction and growth of the species, whether or not the species is listed, control action impacts to surrounding habitats, and cost, leading to an appropriate control method. It may be useful to incorporate models that assess control option efficacy as well as economic benefit and control costs (Buhle et al. 2005).

Issue: A protocol for specific lines of communication among states and agencies planning to move forward in controlling a non-native fouling species is lacking.

Recommendation: Using ICS or the WCGA, gather managers to develop protocols for determining action options.

Task A: Determine the extent of the non-native species' impact and damage incurred among states.

Task B: Determine the economic feasibility of control, including a timeline. If action is determined to be economically unfeasible, or the potential impacts of the non-native species are not determined to outweigh the costs of control, no action may be selected. 
Task $C$ : Determine the most effective control methods using the decision matrix, incorporating input from the scientific advisory team.

Task D: Develop species-specific protocols for the selected control methods. Designate responsibility for the execution of specific control methods.

Issue: Control methods research needed for large scale control of fouling species. More specific tests of control methods are needed.

Recommendation: Develop contacts and plans for attracting and applying for funding to increase research opportunities assessing control methods, implemented at large scales. Build relationships with university partners to create research programs. 


\section{Conclusion}

The Pacific Regional Biofouling Management Plan aims to bring Oregon and Washington management entities together to address the threat of coastwise spread of non-native fouling species. Each state conducts prevention, early detection, rapid response, and control of existing nuisance species, independently, but the fluid nature of coastal systems and operations require coordination for such efforts to be successful in the long term. As a uniform guidance document, this framework will help to develop communication between states about projects conducted in each management phase. It will also help guide the development of vector management practices.

By focusing attention on vector operations, this plan addresses the threat of many non-native species within the fouling community simultaneously. Prevention and regulatory efforts in particular are aimed at vectors and management of each will require coordination between multiple agencies. Surveying and monitoring efforts are promoted in this plan as their execution is essential to for the detection of new species as well as assessing their impacts. This framework addresses gaps in management of these vectors by attempting to identify agencies or systems that may have authority over each vector at various stages of management.

This plan is meant to inform managers of the potential for biofouling management, provide information on the scope of effective management based on previous plans, and offer guidelines for non-native biofouling management developed in scientific literature and existing plans. Methods for evaluating the efficacy of the management recommendations described in the framework need to be developed by 
managers in order to change practices as necessary. Coastal management of biofouling is the goal of coordinated management efforts and groups such as the Western Regional Panel Coastal Committee are building on the momentum for managing marine invasive species with plans to develop a comprehensive biofouling plan across western coastal states, informed by this and other efforts. 
Chapter 3: Prey structure, caloric content, and predator characteristics influence predation rates on native versus non-native ascidians

\begin{abstract}
Non-native species can threaten economic and environmental health, making it crucial to understand factors that make them successful. Identifying such factors allows for greater preparedness and informed management of biological invasions and increases understanding of elements structuring biological communities. In the marine environment, many colonizing non-native ascidian species have been quite successful on, but limited to, anthropogenic structures, and this may be influenced by species characteristics and relative predation risk across habitats. I observed that native softbodied predators were common on colonies of a native ascidian, Distaplia occidentalis, but not on the non-native clonal ascidians fouling the same docks, Botrylloides violaceus and Botryllus schlosseri. My objectives are to: 1) test the hypothesis that suspended structures, like docks, are more invasible than benthic habitats; and 2) identify characteristics influencing predation patterns on the native Distaplia occidentalis versus non-native ascidian species using a series of feeding assays, surveys, and a caloric content analysis. A quantitative survey of Charleston Marina, Oregon, USA, in 2014 indicated that the native $D$. occidentalis was depredated in the suspended environment by the nudibranch Hermissenda crassicornis and the flatworm Eurylepta leoparda, but these
\end{abstract}


predators were never found on nearby colonies of $B$. violaceus. I tested the hypothesis that benthic predators depredate native and non-native ascidians, while suspended predators depredate native ascidians. I also aimed to identify if observed predation patterns on artificial substrata are attributable to differences in palatability characteristics

of native versus non-native ascidian species. Experiments included two benthic predators and two predators also found in the suspended environment and compared predation rates on whole ascidian colonies, chemical extracts of ascidians in squid paste, and blended ascidian samples mixed with squid paste. Eurylepta leoparda was found to be highly selective on the native ascidian Distaplia occidentalis, and only preyed on whole colony samples. Feeding assay data suggest that test (tunic) structure may be a key factor influencing Hermissenda crassicornis predation rates on native versus non-native ascidians, in favor of the native ascidian species. Non-native ascidians may escape predation in suspended but not benthic environments on the Oregon coast due to their palatability characteristics, specifically tunic structure and low caloric content. In this case, this suite of predators may indirectly facilitate the invasion of docks but provide a small degree of resistance to the invasion of natural benthic areas.

\section{Introduction}

Non-native species in coastal marine habitats damage marine infrastructure and threaten native species (Ruiz et al. 2000). Non-native marine species are primarily transported via shipping, and are therefore, often concentrated within harbors and bays, especially the non-native species found in fouling communities (Wasson et al. 2001, Bax 
et al. 2003). Fouling communities are composed of sessile invertebrates and strongly associated mobile species. Ascidians are one of the dominant taxa in fouling communities on anthropogenic marine structures and have raised a significant amount of management concern due to their negative impacts (Lambert 2007). Ascidians can outcompete other species for space, overgrowing recruits and attaching to available hard substrate including mussels and oysters (Dijkstra et al. 2007, Osman \& Whitlatch 1995). Non-native ascidians have negatively impacted mariculture profits by establishing on infrastructure, fouling extensively, and subsequently diminishing growth of product species (Locke et al. 2007, Bullard et al. 2007). Artificial structures host non-native ascidian propagules that threaten to establish in native benthic communities (Simkanin et al. 2012, Lengyel 2009). The threats posed by non-native ascidians make it crucial to understand the interactions between recipient fouling communities and the invading species.

Characteristics of the recipient environment and of the invading species influence invasion success of propagules transported to novel habitats (Levine \& D’Antonio 1999, Kolar \& Lodge 2001). Although non-native ascidian distributions may be primarily influenced by environmental conditions (Grey 2011), where abiotic conditions allow for the establishment of a non-native species, their success is additionally impacted by biotic interactions. Competition or predation interactions in recipient communities may offer biotic resistance to establishment and spread (Kimbro et al. 2013). Studies evaluating competition show that more diverse competitor communities tend to have greater biotic resistance to invasion at local spatial scales (Naeem et al. 2000, Kennedy et al. 2002). In 
fouling communities, Stachowicz et al. $(1999,2002)$ found that competition for the valuable resource of substrate space can limit the growth of non-native species most when community diversity is high. This limit to growth, or resistance, is likely due to the temporal growth variations of fouling species, limiting growth of non-natives across space and time (Stachowicz et al. 2002). Predation may also be an important source of biotic resistance to invasion, especially over the long term (Carlsson et al. 2009), and has been found to limit geographic distributions of invasive species (de Rivera et al. 2005). Resistance through predation has also been found to limit the distributions of non-native ascidians, utilizing predator exclusion methods (Dumont et al. 2011a). However, few studies have examined how predator diversity affects community invasibility.

Differential ability of predators to overcome prey defenses may mean that diverse communities are more likely to contain predators that can prey on introduced species, offering biotic resistance. Shea \& Chesson (2002) present an invasions ecology framework based on community ecology theory that includes the function and impact of generalist to specialist predators on invasions. If a recipient community has a high abundance of specialist predators then non-native species will benefit from increased resource availability due to predation on the resident species (Grover 1994). In this case, the non-native species does not experience the deleterious effects of predation and is indirectly facilitated by predation on competing species (Bruno et al. 2003). In fact, a recipient community's degree of specialization of predators and mutualists influences the community's overall invasibility (Sax et al. 2007). For example, systems in which most predators are generalists and mutualists are specialists prove difficult to invade as 
predation pressure is high on non-natives and natives are supported through mutualist interactions (Parker et al. 2006). Communities with greater generalist predator abundance negatively affect non-native species, potentially negating or overwhelming any indirect facilitative effects of specialist and generalist predation on resident species (Shea \& Chesson 2002). Greater diversity in the predator community may increase the likelihood that there are generalist predators offering such biotic resistance. The ability of generalist predators to recognize non-native species as food and overcome prey defenses (components of non-native species palatability characteristics) determines the community's degree of biotic resistance and invasibility. The effect of palatability characteristics on predators may determine a non-native species' invasiveness in the recipient community.

Many ascidian species have palatability characteristics such as acidity and other chemistry (secondary metabolites), structural defenses, and/or reduced caloric content that deter predation (Stoecker 1978, 1980a, 1980b, Lindquist et al. 1992, Pisut \& Pawlik 2002), though the effect of these characteristics on survivorship across the variety of predator species in a system is not well understood. Chemical defenses (secondary metabolites and acidity) reduced predation in feeding assays that used chemical extracts of different ascidians (Vervoort et al. 1998, Pisut \& Pawlik 2002, Odate \& Pawlik 2007, Koplovitz et al. 2009). Although ascidian palatability studies have primarily been conducted to test chemical defenses, it is likely that many species have physical characteristics such as tunic toughness and spicules that function as defenses against predation (López-Legentil et al. 2006, Koplovitz and McClintock 2011). The palatability 
or defense characteristics of ascidians are highly variable and are influenced by both physical and chemical components of the species as well as the life stage of the organism (Tarjuelo et al. 2002, Pisut \& Pawlik 2002).

Chemical defenses may deter some predator species but not others (Tarjuelo et al. 2002, Pisut \& Pawlik 2002, López-Legentil et al. 2006). Despite this variability in defense characteristics and their efficacy, many ascidian palatability studies focus on fish predators (Vervoort et al. 1994, Pisut \& Pawlik 2002, Koplovitz \& McClintock 2011), with only a few incorporating at least one invertebrate predator (Simoncini \& Miller 2007, Koplovitz et al. 2009, Stoecker 1980a). Some invertebrates, however, such as opisthobranchs and polyclad flatworms, have been found to specialize on ascidians, often sequestering their prey's chemical defenses for their own protection against predators (Millar 1971, Paul et al. 1990, Kubanek et al. 1995). Palatability studies may be conducted in an invasions ecology context (Lages et al. 2006) to assess a species' invasiveness, although no ascidian palatability studies have been conducted to quantitatively compare non-native and native species. Differences in palatability characteristics can be important for understanding species or taxa invasiveness, particularly if a community is dominated by specialist predators that have co-evolved with native species.

In Charleston Marina, Oregon, I observed predation patterns on native and nonnative ascidian species, and noted potential specialist predators on a native ascidian along the docks (suspended structures). In this fouling community, the native ascidian Distaplia occidentalis and non-native ascidian Botrylloides violaceus were the most 
commonly observed. The potential predators I noted were a flatworm and a nudibranch, each taxon sometimes known to specialize on ascidians (Millar 1971). Based on this potential predator specialization on a native species, I hypothesized that docks are more invasible than nearby benthic areas. This is consistent with studies that have found few or non-existent predation patterns on suspended structures, while benthic habitats have greater predator diversity and biotic resistance to non-native ascidian species (Dumont et al. 2011a, Simkanin et al. 2011, Forrest et al. 2013). This hypothesis also fits the pattern of non-native species concentration on anthropogenic structures and limited distributions in the benthos. Benthic predators, particularly crustaceans, tend to be more generalist and many such benthic predators may not have access to or reason to pursue prey on the docks, high above the benthos. If one or more of the predators found on docks were not in fact specialists, palatability studies may be conducted to determine if there is a specific characteristic that makes the native ascidian more attractive as prey. Therefore, my objective was to test for any potential defenses influencing predation patterns in benthic and suspended habitats, evaluating Botrylloides violaceus invasiveness compared to a putative native competitor.

I tested the hypothesis that ascidians on suspended structures face less biotic resistance from predation than ones in benthic habitats and addressed my objective to assess palatability through a series of surveys, feeding assays, and caloric content analyses. The surveys quantified predator-prey interactions in the field. The feeding assays yielded feeding rate measurements that show the influence of structural and chemical palatability characteristics on predation on each ascidian species. I examined 
the palatability of native (Distaplia occidentalis) and non-native (Botrylloides violaceus) ascidians across a suite of four predators from two habitat types (with two benthic predators, the shore crab Hemigrapsus oregonensis and the hermit crab Pagurus granosimanus, and two suspended predators, the flatworm Eurylepta leoparda and the nudibranch Hermissenda crassicornis). Caloric content analysis provided information on how attractive each species is as food. Through this study I aim to identify if non-native ascidians escape predation in suspended but not benthic environments on the Oregon coast due in part to their palatability characteristics, in which case predators may indirectly facilitate the invasion of docks but provide resistance to the invasion of natural benthic areas.

\section{Methods}

Surveys

In order to quantify predation patterns and test differences between the native ascidian and the non-native ascidian, I conducted two surveys of abundance and predation on the docks of Charleston Marina, Oregon, USA, in the late summers of 2014 and 2015. The goals were to: a) identify predators of ascidians on suspended structures; and b) note whether predator-ascidian association differed between native and non-native species of clonal ascidians. Both the native Distaplia occidentalis and the non-native Botrylloides violaceus were common during the initial survey of dock structures in summer 2014. I recorded observations of predation on ascidians by starting at 32 randomly selected points of the marina along the docks to obtain good coverage (Gotelli 
\& Ellison 2004), I proceeded to the first spotted colony of each ascidian species (if present on the slip) and recorded any associated predators, looking for signs of feeding. In order to provide strong evidence of predation in the field, I first looked for nudibranch buccal movement while the nudibranch predator was on the ascidian prey. Second, I noted signs of discoloration and grooves along flatworm feeding paths on otherwise healthy ascidian colonies. In addition, I noted orange coloration along the flatworms' stomachs that disappeared when separated from ascidian prey over a few hours.

Distaplia occidentalis was present at each observed dock slip, but B.violaceus and B. schlosseri were missing from 12 and 22 of the 32 observed slips, respectively. The summer of 2015 yielded very few colonies of $D$. occidentalis. I made observations of each D. occidentalis colony grouping I found throughout two days of searching the inner and outer marinas, spread across six slips of the inner, small boat marina. For each observation of $D$. occidentalis, I also examined the nearest colony of the now more abundant $B$. violaceus. Predator presence on individual colonies and density on individual colonies were recorded by counting. In addition, I made observations of other potential prey species for the flatworm Eurylepta leoparda across 22 of 264 dock slips of the inner marina (where the flatworm was found), to verify its prey selectivity for the native ascidian $D$. occidentalis. I recorded species seen across a random $25 \mathrm{~cm}$ section on the side of the dock. I observed Botrylloides violaceus ( $\mathrm{n}=46$, across 18 slips) Styela clava $(\mathrm{n}=16$, across 7 slips), Botryllus schlosseri ( $\mathrm{n}=18$, across 11 slips), bryozoans including Schizoporella pseudoerrata and Cryptosula pallasiana ( $\mathrm{n}=19$, across 16 slips), and sponges including Halichondria panicea and Haliclona permollis $(\mathrm{n}=22$, across 12 slips). To test the different quantities of observations of predation on the native versus 
the non-native ascidian for each year, I analyzed survey data using Fisher's exact tests due to small sample sizes.

\section{Caloric Content}

In order to determine how attractive or rewarding ascidian species are as food, caloric content data were collected from samples in Charleston Marina, OR. I scraped independent ascidian colonies off the docks and extracted uniformly sized samples, the width of a $20 \mathrm{~mm}$ PVC pipe, to be used for analysis. Due to a limited number of Distaplia occidentalis colonies but aiming for uniformity across ascidian species for statistical tests, I collected five samples of six ascidian species to determine average caloric content per species. Four non-native species were analyzed including two colonial ascidians (Botrylloides violaceus, Botryllus schlosseri) and two solitary ascidians (Styela clava, Molgula manhattensis). The two native species analyzed include the colonial Distaplia occidentalis and the solitary Corella inflata. These six species represent the entirety of the observed ascidian biomass on these docks at the time of sampling.

Immediately following collection, samples of similar sizes were frozen for several days at $-4{ }^{\circ} \mathrm{C}$. I then desiccated samples in an oven for 8 hours at $80{ }^{\circ} \mathrm{C}$. Following this desiccation, samples were weighed to the nearest 0.001 gram. I then determined ash-free dry weight (AFDW) by burning samples in a muffle furnace for 24 hours at $440{ }^{\circ} \mathrm{C}$. To standardize grams of AFDW to joules, I used the factor of $19.7 \mathrm{~g} / \mathrm{J}$ as identified for ascidians (Brey et al. 1988). Following tests for one-way ANOVA assumptions that were met by the caloric content data, I analyzed the influence of species identity comparing 
native and non-native species, as well as colonial and solitary species on caloric content values through one-way ANOVAs. I also used an ANOVA to directly compare the two colonial ascidian species used in feeding assays, the native Distaplia occidentalis and the non-native Botrylloides violaceus. Data for these two species met the assumptions of a one-way ANOVA.

Feeding Assays

Palatability of native versus non-native ascidians was evaluated by determining the influence of structural, chemical, and caloric differences on predation rates. The feeding assays, paired with additional analyses of caloric content, aimed to isolate the influence of particular palatability characteristics of each species. The first assay determined feeding rates on whole colony samples of each ascidian species by pairing an individual predator with one ascidian sample in a separate tank for a feeding period. The second assay aimed to test the influence of physical structures, such as spicules, as well as the influence of the absence of ascidian tunics by blending ascidian samples and mixing them in squid paste. It is possible that the chemistry could also change with this blending. The third assay tested chemical (secondary metabolite) defenses against predation by combining ascidian chemical extracts with squid paste.

The native Distaplia occidentalis and non-native Botrylloides violaceus were selected as prey species as these were the two most common species per category of ascidian. I conducted three separate feeding assays across a suite of four predators, including two predators found on suspended structures (the flatworm Eurylepta leoparda and the nudibranch Hermissenda crassicornis) and two predators found only in the 
benthos (verified through dock surveys of predators, the hermit crab Pagurus granosimanus, and the shore crab Hemigrapsus oregonensis). It is possible that using a set number of predators for each assay (naïve in each assay), may have allowed individuals to become accustomed to experimental foods. However, other studies introducing whole samples of food to predators followed by a chemical extract assay do not note any issues with the resulting data (Odate \& Pawlik 2007, Tarjuelo et al. 2002). For each assay, predators were haphazardly selected for exposure to either the native or non-native ascidian prey species, independent of previous assay exposure.

Individual flatworm and nudibranch predators with lengths $\geq 11 \mathrm{~mm}$ were collected from the marina and nearby benthic habitats, in order to collect adult predators that likely have a larger impact on ascidian biomass. The nudibranchs had wet weights ranging from $0.24-4.30 \mathrm{~g}$. Flatworms, when elongated, ranged in size from $11-30 \mathrm{~mm}$ long. Hermit crabs were no less than 6 grams of wet weight, with the largest reaching 13.4 g. Shore crabs had carapace widths between $11-20 \mathrm{~mm}$. I visually assessed predator size when selecting them for each assay, and aimed for experimental balance. To test that there was no bias between size of predators in the native prey category and the non-native prey category, I conducted one-way ANOVAs (one per nudibranch and shore crab predators for each feeding assay) to assure that the prey identity did not significantly influence predator size distribution in the assays. I collected data on the size of the nudibranch and shore crab predators to be compared to feeding rates. These data were collected during the feeding assays and in order to test for a relationship between size and feeding rates I used Pearson's product-moment correlational analysis. To meet the assumptions of this analysis, data was square root transformed. Where the 
relationship was significant, I followed up correlation analysis with a simple linear regression. Nudibranch wet weights (g) were recorded using a scale; for the shore crab, H. oregonensis, carapace width $(\mathrm{mm})$ was measured by ruler. For each of the three assays, I followed the same feeding protocol described below.

Experimental work was completed at the Oregon Institute of Marine Biology (OIMB) in summer 2015. Predators were stored according to species, in large tanks with flow-through seawater at OIMB prior to being selected for feeding assays and placed in an individual container. I fed predators a preferred food prior to the start of a $24 \mathrm{hr}$ (Hermissenda crassicornis, Eurylepta leoparda) or $48 \mathrm{hr}$ (Pagurus granosimanus, Hemigrapsus oregonensis) starvation period, to allow each species to become hungry, having determined these durations through pilot studies. The following protocols are based on existing feeding assay literature (Young 1986, Stachowicz \& Lindquist 1997, Pisut \& Pawlik 2002, Tarjuelo et al. 2002, Epelbaum et al. 2009) and my own pilot work to develop sound methods and appropriate time periods for these particular species. Individual predators were tested for hunger with a preferred food prior to being placed in these experimental containers and only advanced to the experimental trial if they ate at this time. Predators were experimentally naïve for each feeding assay. I allowed time for predators to move about their new surroundings, about two hours or until they stopped, whichever came later. Then, the appropriate ascidian species or squid-ascidian paste was presented to the predator. I weighed, to the $0.001 \mathrm{~g}$ of wet weight, each towel-dried ascidian sample before and after the designated feeding period. After allowing predators the chance to feed on the ascidian samples over three hours (determined to be sufficient time for measurable predation on ascidians through pilot studies), predators were again 
tested for hunger with a preferred food to make sure they were still feeding and had not been satiated, potentially skewing predation rate data (Stachowicz \& Lindquist 1997, Pisut \& Pawlik 2002, Tarjuelo et al. 2002). Data from predators that did not feed on the preferred food following the assay were discarded ( $\mathrm{n}=1$, hermit crab), as any feeding within the 3-hour period may not be an accurate representation of feeding or grazing rates. Placement of the predator/ascidian combinations was randomized across the laboratory tanks to alleviate any environmental effects within the lab. The experiment proceeded across two to four time blocks, with sample size varying based on predator availability, each with three replicates of each predator-ascidian combination (Figure 1). A lack of space and experimental time constraints made time blocks necessary, but because all conditions remained uniform across blocks, no variation in feeding rates by block was expected. 


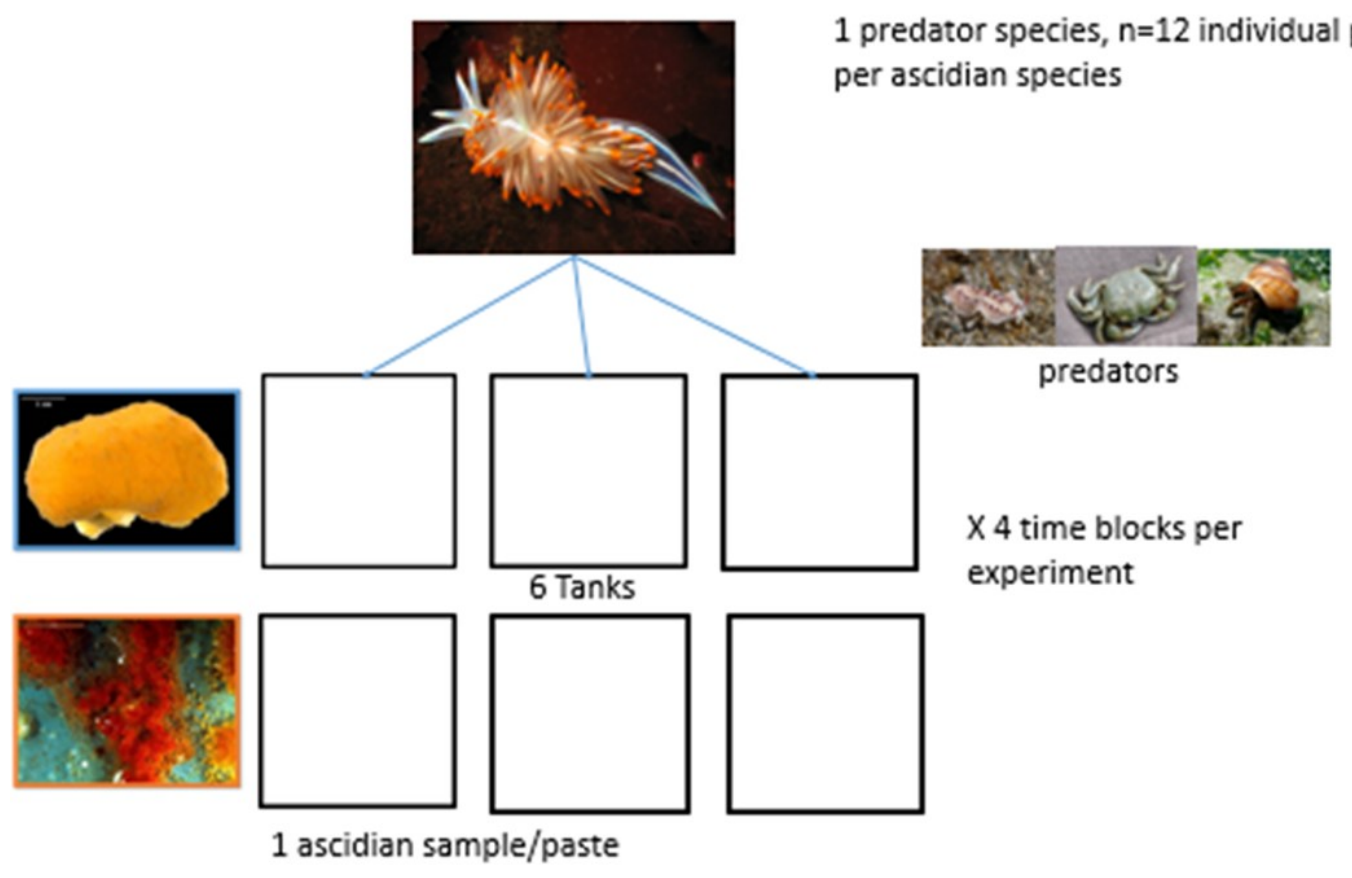

Figure 1 Schematic of feeding assay study design showing one predator and one ascidian sample paired per tank across 24 total tanks, 6 tanks per predator times 4 time blocks

Based on feeding assays conducted by Tarjuelo et al. (2002), Epelbaum et al. (2009), and Pisut \& Pawlik (2002), I aimed to obtain 12 replicates per predator-ascidian pair (Figure 1). However, in 2015 predator numbers in the suspended environment were low, limiting the number of replicates in the following cases. First, although 17 replicates per ascidian species for the nudibranch Hermissenda crassicornis were available for the whole colony feeding assay, due to nudibranch escape, the remaining feeding assays for this predator had 9 replicates per ascidian prey species. Second, the flatworm Eurylepta leoparda had 6 replicates per ascidian prey species. The full twelve replicates were achievable for each of the two benthic predators, and the relationship between the flatworm and the native ascidian is strong enough to have been detected with $\mathrm{n}=6$. The flatworm was the only predator that did not produce data for each feeding 
assay. This species proved very selective of prey and would not feed on any form of the native ascidian paste, only the whole colonies.

Additional predator/ascidian combinations were tested to detect other interactions occurring in the suspended environment. Other predators collected from the docks included the nudibranchs Triopha catalinae and Peltodoris nobilis, the kelp crab Pugettia producta, and skeleton shrimp Caprellidae spp. These potential ascidian predators were fed either a whole colony sample of the native Distaplia occidentalis or the non-native Botrylloides violaceus. Control samples of ascidians or ascidian-squid pastes were measured to account for potential weight gain and variation in wet weight measurements during the feeding trials. Control factors were incorporated into feeding rates by subtracting average change in wet weight (g) per hour in the controls ( $\mathrm{n}=3$, per ascidian species) from the feeding rate values of each experimental replicate.

For the blended ascidian assay testing the influence of a de-structured tunic on feeding rates, I mixed blended ascidians with agar, water, and blended squid using the same proportions as Pawlik et al. (1995). The ratio of ascidian to squid used was 1:1 and I used 5 colonies per species blended together. I tested that squid pastes were consumed by all predators and all fed readily on the squid pastes, except the flatworm. Mixing a preferred or known palatable food for the predators with the ascidian components entices the predators to at least try the novel food, showing that the ascidian components have either deterred or not deterred consumption (Stachowicz \& Lindquist 1997). This deterrence, or lack thereof, is then reflected in the overall predation rates. I created soft food pellets from the pastes using sodium alginate and calcium chlorate as in Pawlik et al. (1995), so that the food maintained its structure in the seawater. 
I used crude chemical extracts from 3 individuals per ascidian species. Prior to extraction, ascidian samples were frozen to negate the influence that species acidity may have on predation rates, isolating secondary metabolites (Stoecker 1980a, Lages et al. 2006, Odate \& Pawlik 2007). My extraction process was based on Stachowicz \& Lindquist (1997) and Pawlik et al. (1995), but was less stringent as my aim was only to extract the essence of the ascidians, free of spicules, without focusing on particular chemical compounds. Ascidians were extracted once after being crushed in a tissue homogenizer, using 1:1 water and dichloromethane at a volume of $20 \mathrm{ml}, 22 \mathrm{ml}$ with homogenized ascidian. I used a $10 \mathrm{ml}$ syringe to collect the extracts and expelled them from the syringe onto a clean petri dish surface to dry under a fume hood. After drying, the extracts were mixed into an amount of squid paste equal to the initial wet weight of the ascidians. This paste was then gelled into individual pellets using the same process as in the blended assay.

Data analysis followed protocols for first conducting exploratory analysis and obtaining measures of spread, then, testing normality with a Shapiro-Wilkes test and variance with an $\mathrm{F}$ test. Feeding assay data were then transformed, if needed, by adding the smallest possible value (10) to eliminate negative or zero values allowing me to square root transform each data point. This transformation was done in order to achieve normality. I then analyzed data using two sample t-tests or Welch's two sample t-tests, depending on violations of assumptions of equal variance, to compare predation rates on the native versus non-native ascidians per predator species. I conducted a mixed twoway ANOVA with time blocks as a random factor to evaluate the influence of ascidian prey species and habitat of the predator (with predator species nested) on feeding rates. I 
then conducted a post-hoc analysis using Tukey's Honestly Significant Difference test to determine which factor pairs have significant differences in feeding rates.

\section{Results}

Survey

The surveys revealed different predation pressure on native vs. non-native ascidians. In 2014, 12 of 32 (37.5\%) observed native Distaplia occidentalis colonies were being consumed through flatworm or nudibranch predation, whereas no predators were found on non-native Botrylloides violaceus or Botryllus schlosseri colonies. Differences in the number of observations of soft-bodied, suspended structure predators (combined: Hermissenda crassicornis, Eurylepta leoparda) depredating D. occidentalis versus $B$. violaceus (Fisher's exact test: $\mathrm{n}=52, \mathrm{p}_{2 \text {-tailed }}=0.0016$ ), and $D$. occidentalis versus $B$. schlosseri (Fisher's exact test: $\mathrm{n}=41, \mathrm{p}$ 2-tailed $=0.0392$ ) were statistically significant. No evidence of predation by flatworms on species other than $D$. occidentalis was found in a survey of 22 slips looking at 7 potential prey taxa. Surveys of nearby benthic areas, above water at low tide, showed no colonies of any colonial ascidian species (i.e., D. occidentalis, B. violaceus, or B. schlosseri).

The survey in 2015, when $D$. occidentalis was less common, showed that $D$. occidentalis colonies with predators had multiple flatworms consuming them, occasionally with more surface areas of the colony covered with flatworms than exposed. The average number of adult flatworms per D. occidentalis colony was 2.33 individuals $(n=6)$. A total of six D. occidentalis colonies, or cluster of colonies, were found, and 
observed and paired with a $B$. violaceus colony. No B. violaceus colonies observed showed signs of predation. No other potential Eurylepta leoparda prey species such as Styela clava, Botryllus schlosseri, Schizoporella pseudoerrata, Cryptosula pallasiana, or sponges including Halichondria panicea and Haliclona permollis were found with predators or with signs of having been consumed across 22 surveyed slips.

\section{Caloric Content}

Distaplia occidentalis has greater caloric content (calories/g of dry weight) than the non-native ascidian Botrylloides violaceus, though this relationship was not statistically significant at $\alpha_{\text {crit }}=0.05$ given five samples per species (Figure 2, ANOVA: $\left.\mathrm{F}_{1,8}=4.655, \mathrm{p}=0.063\right)$.

The ANOVA testing differences in caloric content between colonial versus solitary ascidians indicated a weak relationship, though not statistically significant at $\alpha_{\text {crit }}$ $=0.05\left(\right.$ Table $\left.1 \mathrm{~F}_{1,28}=3.646, \mathrm{p}=0.066\right)$. Mean caloric content per gram of dry weight for colonial ascidians was 130.702 calories $+/-50.53$ (SD) and mean for solitary ascidian caloric content was 189.588 calories $+/-108.216$ (SD). Native species caloric content was not significantly different from non-native species caloric content (Table $2 \mathrm{~F}_{1}$, $28=0.16, \mathrm{p}=0.7)$. 
Table 1 One-way ANOVA with caloric content (calories/g of dry weight) of ascidian samples as response testing the influence of native versus non-native ascidian type.

\begin{tabular}{|l|r|r|r|r|r|}
\hline Caloric Content One-way ANOVA & & & \\
\hline & df & \multicolumn{1}{|c|}{ Sum Sq } & Mean Sq & F vahe & p value \\
\hline Colonial vs. Solitary & 1 & 26006 & 26006 & 3.65 & 0.066 \\
\hline Residuals & $\mathbf{2 8}$ & $\mathbf{1 9 9 6 9 6}$ & $\mathbf{7 1 3 2}$ & & \\
\hline
\end{tabular}

Table 2 One-way ANOVA with caloric content (calories/g of dry weight) of ascidian samples as response testing the influence of native versus non-native ascidian type.

\begin{tabular}{|l|r|r|r|r|r|}
\hline Caloric Content One-way ANOVA & & & \\
\hline & df & \multicolumn{1}{c|}{ Sum Sq } & Mean Sq & F vahe & p value \\
\hline Native vs. Non-native & 1 & 1256 & 1255.8 & 0.16 & 0.7 \\
\hline Residuak & $\mathbf{2 8}$ & $\mathbf{2 2 4 4 4 6}$ & $\mathbf{8 0 1 5 . 9}$ & & \\
\hline
\end{tabular}

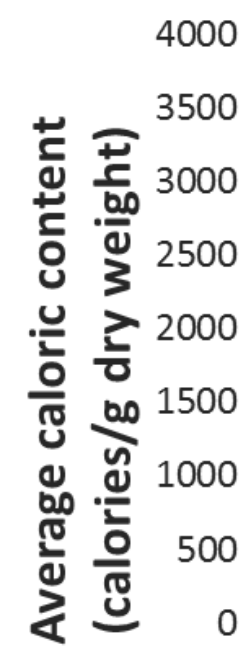

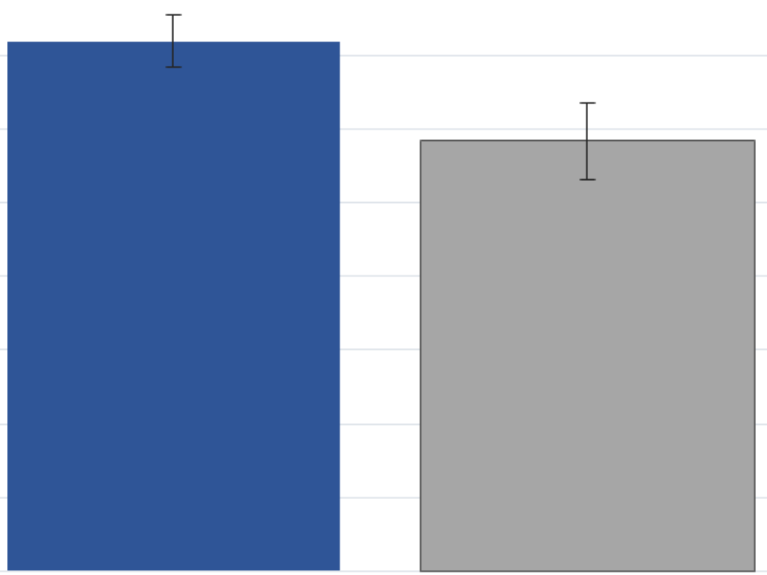

\section{Ascidian species}

Distaplia occidentalis $\square$ Botrylloides violaceus

Figure 2 Mean caloric content per gram of dry weight, + or -1 standard error, of native ascidian (blue) Distaplia occidentalis ( $n=5$ ) and non-native ascidian (light grey) Botrylloides violaceus ( $n=5$ ).

Feeding Assays 
Whole colony feeding assays each yielded significant results (Table 3, Figure 3). Suspended environment predators such as the nudibranch, Hermissenda crassicornis $(\mathrm{n}=17)$ and the flatworm Eurylepta leoparda $(\mathrm{n}=6)$ fed on the native Distaplia occidentalis at significantly higher rates than on non-native B. violaceus (Table 3, Figure 3a, 3b). Eurylepta leoparda did not feed on B. violaceus at any time (Figure 3b). Benthic predators, Pagurus granosimanus $(\mathrm{n}=16)$ and Hemigrapsus oregonensis $(\mathrm{n}=12)$ had clear differences in predation rates as well (Table 3). Pagurus granosimanus fed on non-native Botrylloides violaceus at significantly higher rates (Figure 3c) and $H$. oregonensis fed on native Distaplia occidentalis at significantly higher rates (Figure 3d). Blended ascidian and chemical extract assays yielded no significant differences for any predator (Table 3, Figure 4, 5). Hermissenda crassicornis fed on B. violaceus at slightly higher rates when tunic structure of the ascidians was eliminated (Table 3, Figure 4a), but fed on D. occidentalis extract at marginally higher rates (Table 3, Figure 5a). Throughout the feeding assays, $P$. granosimanus fed on non-native $B$. violaceus at higher rates (Figures $3 c, n=16$, Figure $4 c, n=12$, Figure $5 c, n=12$ ). Although not statistically significant, $H$. oregonensis fed on $D$. occidentalis at slightly higher rates when tunic structure was eliminated (Figure $4 \mathrm{c}, \mathrm{n}=12$ ), but fed on B. violaceus at higher rates when only the extracts of ascidians were mixed with squid paste (Figure $5 \mathrm{c}, \mathrm{n}=12$ ). Eurylepta leoparda did not feed in the blended ascidian nor the chemical extract assay.

The ANOVA evaluating the influence of ascidian prey species and habitat of the predator on feeding rates found a significant interaction between these two factors (ascidian $\times$ habitat of predator, Table 4 ). Figure 6 shows that there is an interaction between ascidian prey identity and habitat of the predator, with suspended structure 
predators having the strongest relationship with ascidian prey identity. Post-hoc Tukey's HSD assessing prey species and predator habitat as factors affecting feeding rates was conducted. The difference in feeding rates for native prey paired with suspended predators and non-native prey with suspended predators was significant (Table 5). Each predator found in the suspended habitat fed on native Distaplia occidentalis at significantly higher rates than on non-native Botrylloides violaceus (Table 3, Figures 3c, 3d). Differences were also significant for native prey with suspended predators compared to non-native prey with benthic predators, as well as native with suspended compared to native with benthic (Table 5).

Table 3 Results of whole colony, blended in squid paste, and chemical extract in squid paste ascidian feeding assays tstatistic, $p$-value, mean predation rate on each ascidian species +/- standard error (SE). *sqrt transformation of data

\begin{tabular}{|c|c|c|c|c|c|}
\hline \multicolumn{6}{|l|}{ Feeding Rates (mg/hr) } \\
\hline & \multicolumn{2}{|l|}{ Whole Colony } & & & \\
\hline Predators & $\mathrm{N}$ & \begin{tabular}{|l} 
Distaplia \\
occidentali s \\
mean $+/$ - SE
\end{tabular} & \begin{tabular}{|l|} 
Botrylloides \\
violaceus mean \\
$+/-\mathrm{SE}$
\end{tabular} & t-statistic & $\mathrm{p}$-value \\
\hline \begin{tabular}{|l|} 
Pagurus granosimanus \\
\end{tabular} & 16 & $4.429+/-0.498^{*}$ & $6.647+/-0.588^{*}$ & 2.8777 & 0.007313 \\
\hline Hemigrapsus oregonensis & 12 & $63.194+/-13.666$ & $15.139+/-4.668$ & 3.3277 & 0.005189 \\
\hline Hermissenda crassicornis & 17 . & $7.945+/-0.409^{*}$ & $5.611+/-0.607^{*}$ & 3.1883 & 0.003193 \\
\hline \multirow[t]{2}{*}{ Eurylepta leoparda } & 6 & $46.528+/-9.454$ & $-4.028+/-1.591$ & 5.2733 & 0.002768 \\
\hline & \multicolumn{2}{|c|}{ Blended ascidian in squid paste } & & & \\
\hline Predators & $\mathrm{N}$ & $\begin{array}{l}\text { Distaplia } \\
\text { occidentalis } \\
\text { mean }+/-\mathrm{SE}\end{array}$ & $\begin{array}{l}\text { Botrylloides } \\
\text { violaceus mean } \\
+/-\mathrm{SE}\end{array}$ & t-statistic & $\mathrm{p}$-value \\
\hline \begin{tabular}{|l|} 
Pagurus granosimanus \\
\end{tabular} & 12 & $25.778+/-5.951$ & $33.667+/-7.276$ & -0.8393 & 0.4103 \\
\hline Hemigrapsus oregonensis & 12 & $78.00+/-12.227$ & $53.944+/-14.439$ & 1.2714 & 0.2169 \\
\hline Hermissenda crassicornis & 9 & $18.37+/-9.17$ & $28.667+/-8.089$ & -0.842 & 0.4122 \\
\hline Eurylepta leoparda & $\mathrm{N} / \mathrm{A}$ & & & & \\
\hline
\end{tabular}




\begin{tabular}{|c|c|c|c|c|c|}
\hline \multirow[b]{2}{*}{ Predators } & \multicolumn{3}{|c|}{ Chemical extract in squid paste } & \multirow[b]{2}{*}{ t-statistic } & \multirow[b]{2}{*}{ p-value } \\
\hline & $\mathrm{N}$ & \begin{tabular}{|l} 
Distaplia \\
occidentalis \\
mean +/- SE
\end{tabular} & $\begin{array}{l}\text { Botrylloides } \\
\text { violaceus mean } \\
+/-\mathrm{SE}\end{array}$ & & \\
\hline Pagurus granosimanus & 12 & $52.417+/-6.811$ & $58.00+/-7.858$ & -0.5369 & 0.5967 \\
\hline Hemigrapsus oregonensis & 12 & $53.278+/-7.504$ & $62.278+/-6.023$ & -0.9354 & 0.3597 \\
\hline Hermissenda crassicornis & & $4.937+/-0.631^{*}$ & $4.134+/-0.428^{*}$ & 1.0536 & 0.3077 \\
\hline Eurylepta leoparda & N/A & & & & \\
\hline
\end{tabular}

Table 4 Two-way ANOVA with feeding rates ( $\mathrm{mg} / \mathrm{hr}$, sqrt) as response, time block included as a random factor and predator species nested in habitat of predator (benthic or suspended) as a factor, the other factor being ascidian prey type (native or non-native).

\begin{tabular}{|l|r|r|r|r|r|}
\hline Feeding Rates (mg/hr, sqrt) & & & & \\
\hline Habitat & df & Sum Sq & Mean Sq & F value & \multicolumn{1}{c|}{ p value } \\
\hline Ascidian & 1 & 4.04 & 4.04 & 0.93 & 0.34 \\
\hline Habitat:Predator & $\mathbf{1}$ & $\mathbf{5 6 . 5 3}$ & $\mathbf{5 6 . 5 3}$ & $\mathbf{1 3 . 0 6}$ & $\mathbf{0 . 0 0 0 5}$ \\
\hline HabitatAscidian & 2 & 41.15 & 20.58 & 4.75 & 0.01 \\
\hline Habitat:Predator:Ascidian & $\mathbf{1}$ & $\mathbf{5 0 . 6 9}$ & $\mathbf{5 0 . 6 9}$ & $\mathbf{1 1 . 7 1}$ & $\mathbf{0 . 0 0 1}$ \\
\hline Residuak & 2 & 126.55 & 63.27 & 14.61 & 0.0002 \\
\hline
\end{tabular}

Table 5 Post-hoc Tukey's HSD with pairwise comparisons of feeding rates for ascidian prey and habitat of predator as factors.

\begin{tabular}{|l|r|r|r|r|}
\hline \multicolumn{2}{|l|}{ Tukey's HSD Post-hoc analysis } & & & \\
\hline Pairwise comparisons & & & & \\
\hline \hline Ascidian:Habitat & difference & lower & upper & \multicolumn{1}{l|}{ adj } \\
\hline Non:Ben-Non:Sus & 1.068 & -0.728 & 2.865 & 0.409 \\
\hline Nat:Ben-Non:Sus & 1.279 & -0.517 & 3.076 & 0.251 \\
\hline Nat:Sus-Non:Sus & 3.045 & 1.162 & 4.927 & 0.0003 \\
\hline Nat:Ben-Non:Ben & 0.211 & -1.495 & 1.917 & 0.988 \\
\hline Nat:Sus-Non:Ben & 1.976 & 0.179 & 3.773 & 0.025 \\
\hline Nat:Sus-Nat:Ben & 1.765 & -0.032 & 3.562 & 0.056 \\
\hline
\end{tabular}


Suspended

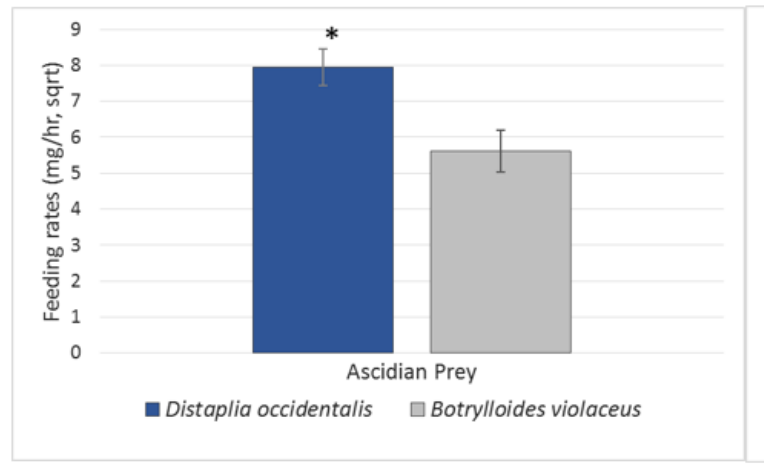

Figure 3a Hermissenda crassicornis

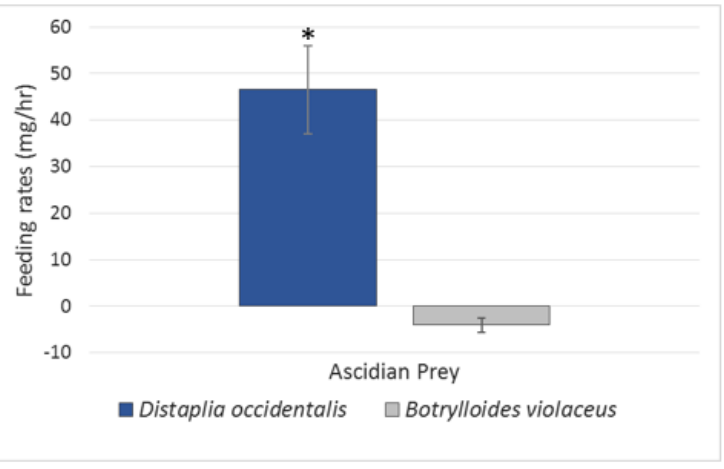

Figure 3b Eurylepta leoparda

Benthic

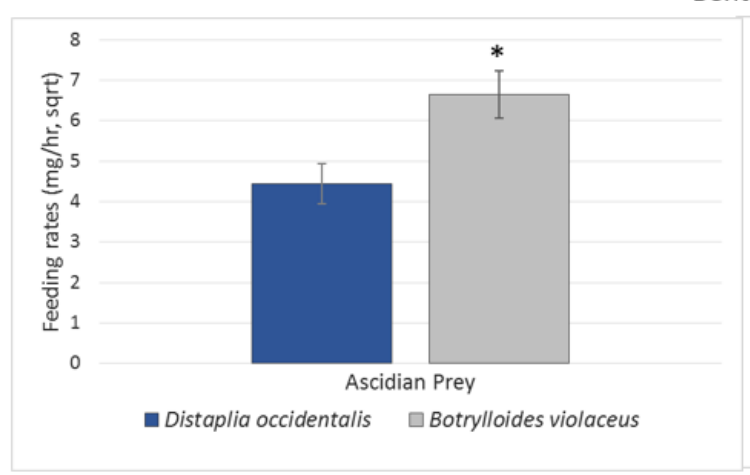

Figure 3c Pagurus granosimanus

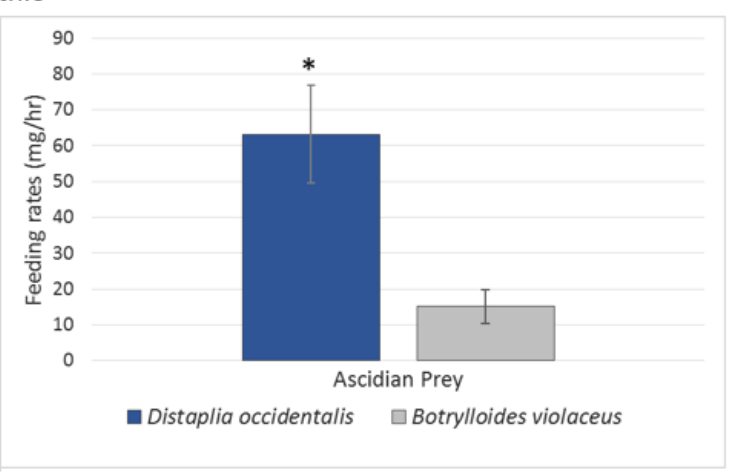

Figure 3d Hemigrapsus oregonensis

Figure 3 Whole colony feeding assay rates ( $\mathrm{mg} / \mathrm{hr}$ ) across four predators, two found on suspended substrata (Hermissenda crassicornis, $n=17$ and Eurylepta leoparda, $n=6$ ) and two not found on suspended substrata and only found in the benthic habitat (Pagurus granosimanus, $n=16$ and Hemigrapsus oregonensis, $n=12$. Feeding rates shown are all relative to the change in the corresponding control treatments. Bars show means $\pm 1 S E$. Asterisks indicate ascidian prey that was consumed at significantly higher rates than other ascidian prey species. 


\section{Suspended}

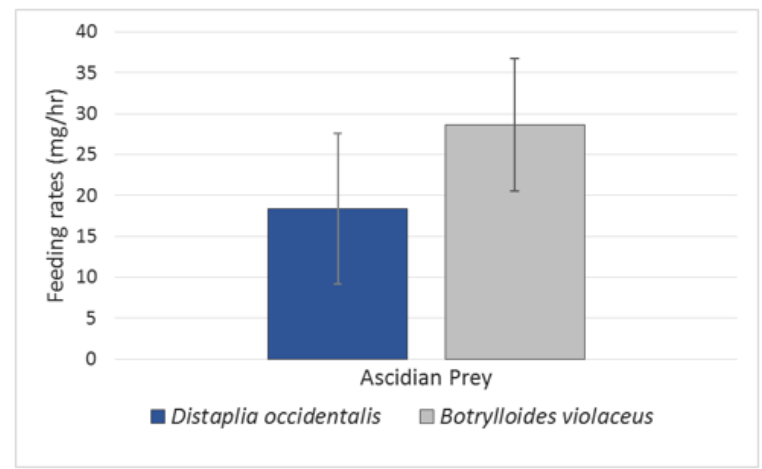

Figure 4a Hermissenda crassicornis

Benthic

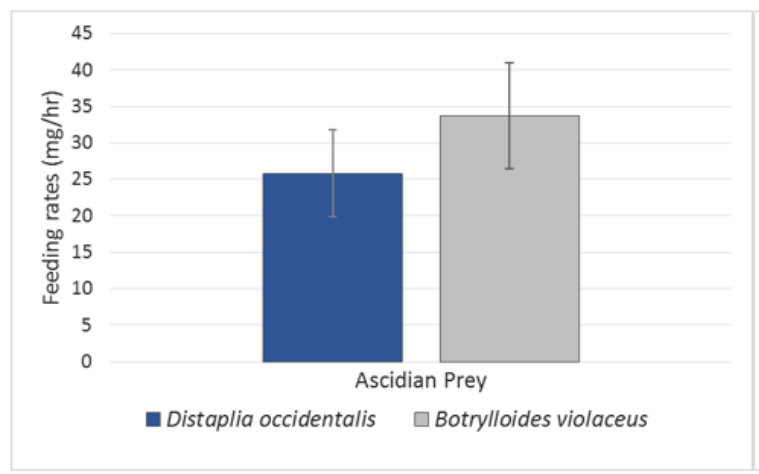

Figure 4b Pagurus granosimanus

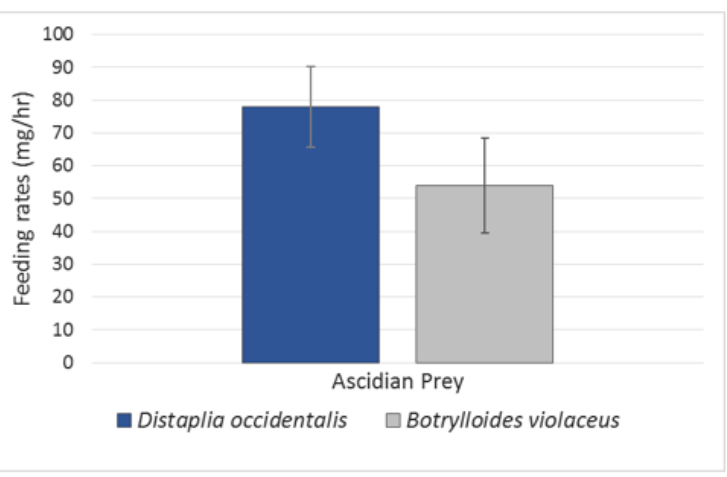

Figure 4c Hemigrapsus oregonensis

Figure 4 Blended ascidian mixed with squid paste feeding assay rates ( $\mathrm{mg} / \mathrm{hr}$ ) across three predators, one found on suspended substrata (Hermissenda crassicornis, $n=9$ ) and two benthic (Pagurus granosimanus, $n=12$ and Hemigrapsus oregonensis, $n=12$. Feeding rates shown are all relative to the change in the corresponding control treatments. Bars show means $\pm 1 S E$. 
Suspended

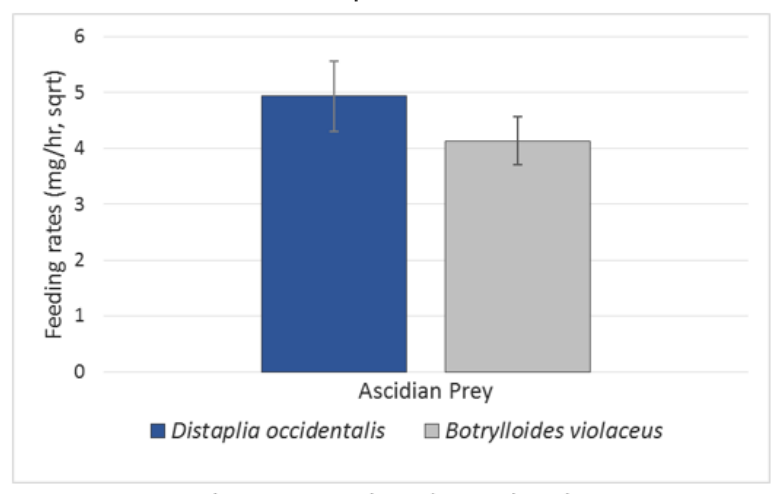

Figure 5a Hermissenda crassicornis

Benthic

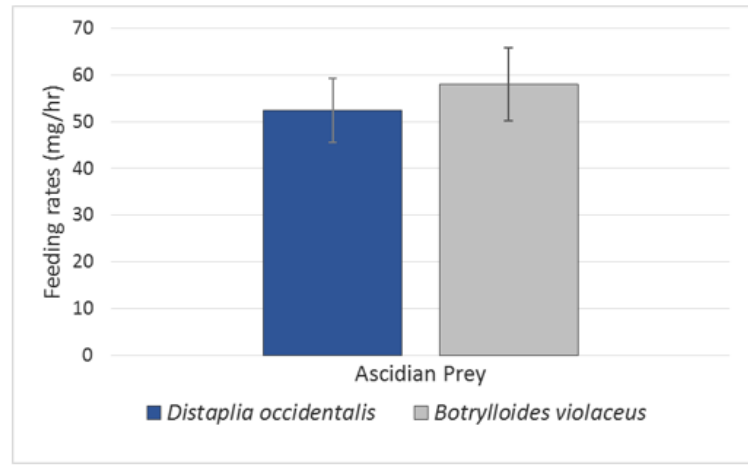

Figure 5b Pagurus granosimanus

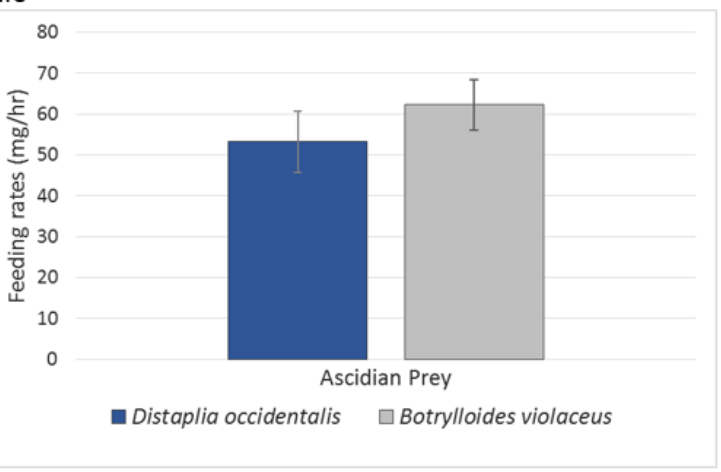

Figure 5c Hemigrapsus oregonensis

Figure 5 Ascidian chemical extracts mixed with squid paste feeding assay rates ( $\mathrm{mg} / \mathrm{hr}$ ) across three predators, one found on suspended substrata (Hermissenda crassicornis, $n=9$ ) and two benthic (Pagurus granosimanus, $n=12$ and Hemigrapsus oregonensis, $n=12$ ). Feeding rates shown are all relative to the change in the corresponding control treatments. Bars show means $\pm 1 S E$. 


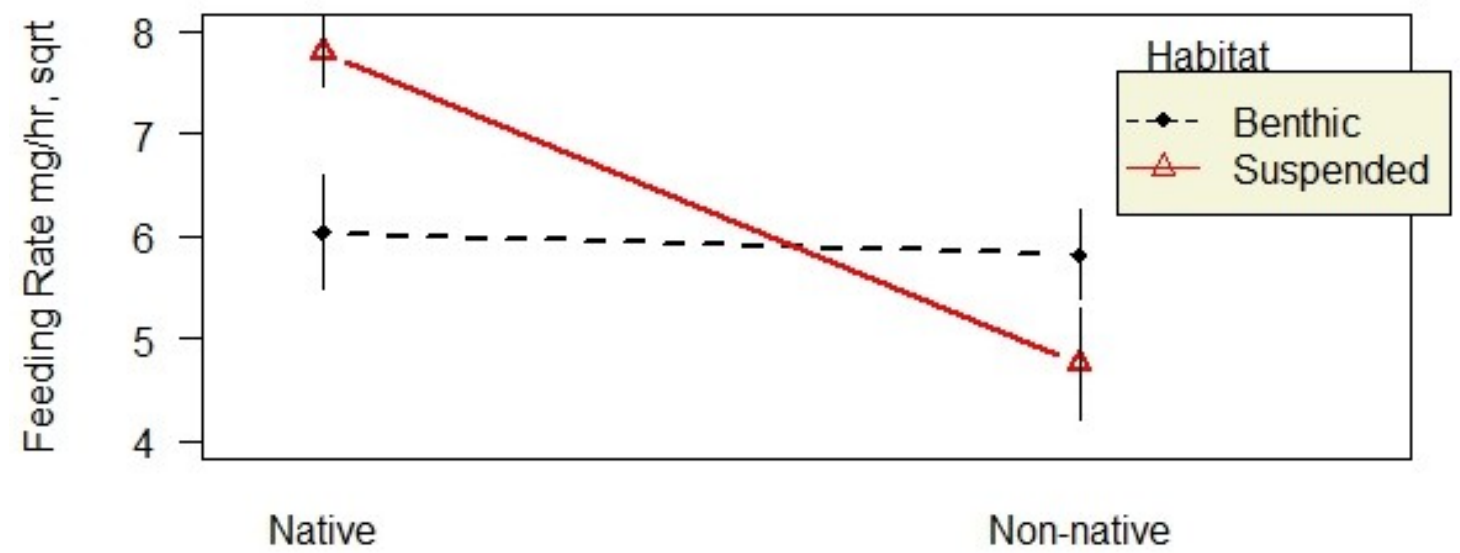

Ascidian

Figure 6 Interaction plot of two-way ANOVA with error bars +/- 1 SD including ascidian prey identity and habitat of predator as factors; feeding rate $\mathrm{mg} / \mathrm{hr}$, sqrt is the response

\section{Predator Size}

Predator size distributions in each feeding assay for the nudibranch and shore crab predators were not significantly different across native and non-native prey categories (Table 6). Size data were normally distributed for each of the one-way ANOVAs, according to Shapiro-Wilkes tests. Prey identity (native or non-native) did not influence either predators' selected size in any feeding assay (Table 6).

Correlation analysis of predator size to feeding rates yielded no significant results for Hermissenda crassicornis and a significant relationship for Hemigrapsus oregonensis. No relationship between Hermissenda crassicornis size and feeding rates was detected $(\mathrm{n}=54, \mathrm{r}=0.17, \mathrm{p}=0.23)$. In contrast, Hemigrapsus oregonensis carapace width and feeding rate data for ascidian prey combined, have a positive correlation $(n=64, r=0.29$ 
$\mathrm{p}=0.019)$. Simple linear regression analysis showed that shore crab size did not have a very strong influence on feeding rates in these assays, as only $8 \%$ of variance in feeding rates is explained by the size of this predator (Figure 7).

Table 6 Predator size distribution data across prey category for each assay and predator (with available data); ANOVA results show no influence of prey category on predator size distribution

\begin{tabular}{|c|c|c|c|c|c|c|c|c|c|}
\hline \multicolumn{3}{|c|}{ Predator Size Distributions } & \multirow[b]{2}{*}{ variance } & \multirow[b]{2}{*}{ SD } & \multicolumn{3}{|c|}{ ANOVA Results } & \multirow[b]{2}{*}{ F-value } & \multirow[b]{2}{*}{$\mathrm{p}$-value } \\
\hline Whole & Prey & mean & & & df & SS & SM & & \\
\hline \multicolumn{10}{|c|}{ H. crassicornis } \\
\hline & Native & 1.362 & 0.251 & 0.501 & 1 & 1.196 & 1.196 & 1.201 & 0.289 \\
\hline & Non-native & 1.878 & 1.519 & 1.232 & & & & & \\
\hline \multicolumn{10}{|c|}{ H. oregonensis } \\
\hline & Native & 15.125 & 6.859 & 2.619 & 1 & 0.391 & 0.391 & 0.044 & 0.838 \\
\hline & Non-native & 15.438 & 8.840 & 2.973 & & & & & \\
\hline \multicolumn{10}{|c|}{$\underline{\text { Blended }}$} \\
\hline \multicolumn{10}{|c|}{ H. crassicornis } \\
\hline & Native & 1.693 & 1.645 & 1.209 & 1 & 0.432 & 0.432 & 0.326 & 0.576 \\
\hline & Non-native & 1.383 & 1.007 & 0.946 & & & & & \\
\hline \multicolumn{10}{|c|}{ H. oregonensis } \\
\hline & Native & 16.667 & 12.606 & 3.399 & 1 & 0.01 & 0.01 & 0.001 & 0.977 \\
\hline & Non-native & 16.625 & 12.415 & 3.373 & & & & & \\
\hline \multicolumn{10}{|l|}{ Extract } \\
\hline \multicolumn{10}{|c|}{ H. crassicornis } \\
\hline & Native & 1.653 & 1.380 & 1.175 & 1 & 0.583 & 0.583 & 0.513 & 0.484 \\
\hline & Non-native & 1.293 & 0.642 & 0.801 & & & & & \\
\hline \multicolumn{10}{|c|}{ H. oregonensis } \\
\hline & Native & 16.250 & 9.188 & 3.031 & 1 & 8.167 & 8.167 & 0.812 & 0.377 \\
\hline & Non-native & 17.417 & 9.243 & 3.040 & & & & & \\
\hline
\end{tabular}




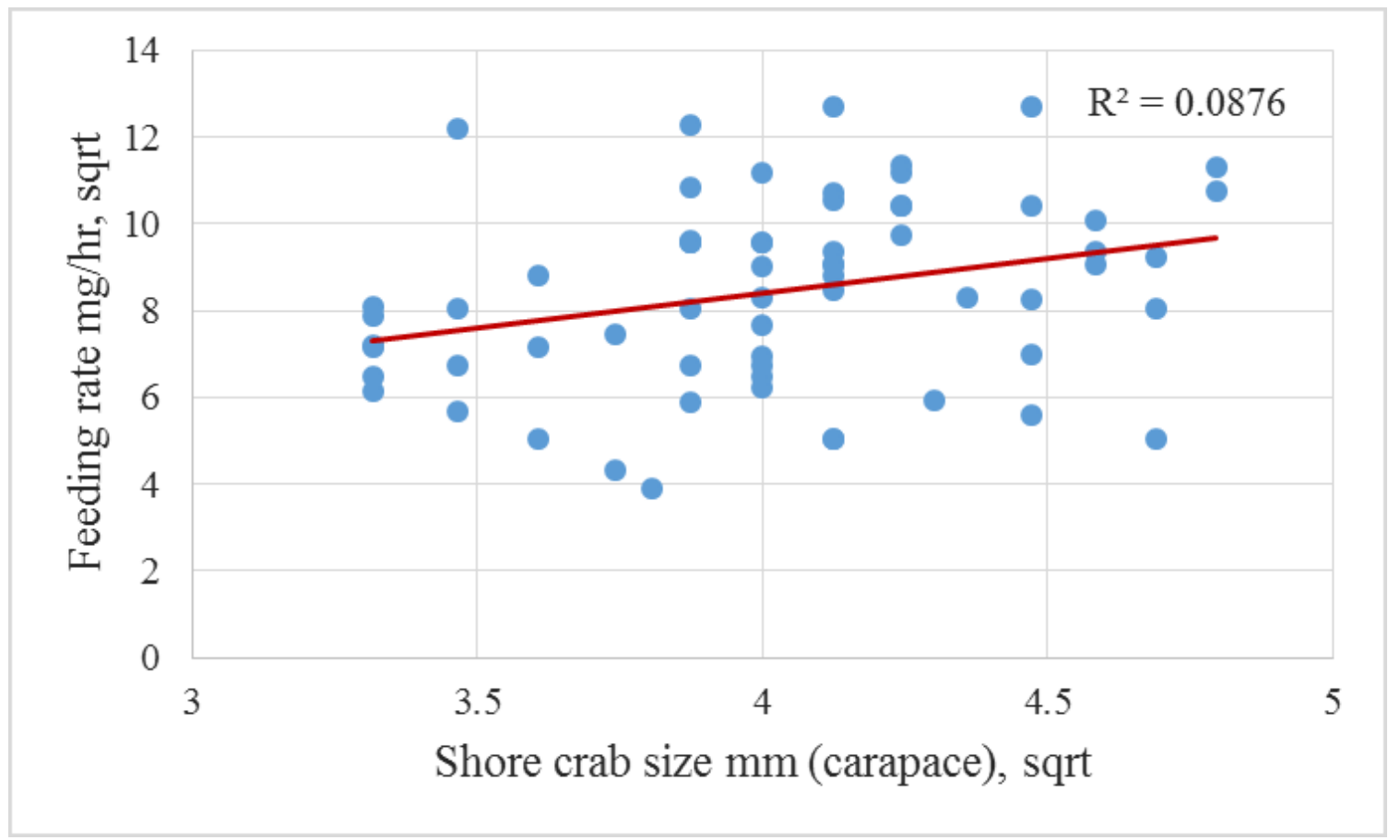

Figure 7 Linear relationship between shore crab (Hemigrapsus oregonensis) size ( $\mathrm{mm}$ ) and feeding rates $\mathrm{mg} / \mathrm{hr}$

\section{Discussion}

\section{Suspended Predation}

Eurylepta leoparda exclusively fed on the native Distaplia ascidian in surveys in Charleston, Oregon and in laboratory experiments in this study. This specialization of a prevalent predator in the suspended environment indicates a situation in which predation may indirectly facilitate the success of non-native ascidian species including Botrylloides violaceus. Such specialization is not unique to Oregon or to E. leoparda and D. occidentalis: flatworm prey preference of a specific ascidian species has also been documented in Spain (Perez-Portela \& Turon, 2007), although both species (predator and prey) are different from those studied here. Surveys of other potential prey of $E$. 
leoparda included bryzoans, sponges, and other ascidians, but no associations were found. The only observed predation by E. leoparda occurred on Distaplia occidentalis. The flatworm's lack of feeding on Distaplia occidentalis in a blended form may be further evidence of its particular association with this native ascidian, as the predator is so specific as to require an intact ascidian structure in order to feed. To determine the extent of specialization, further feeding tests need to be conducted across different life stages of both prey and predator, as well as using other potential prey species from along the Oregon coast. These findings, however, do suggest that E. leoparda is highly specialist on the generalist to specialist spectrum.

The predation patterns of Hermissenda crassicornis across the three feeding assays may indicate that tunic structure or thickness is also likely a key factor driving the avoidance of B. violaceus in the suspended environment that was noted in the 2014 surveys. This nudibranch was observed in 2015 , when D. occidentalis was rare, depredating $B$. violaceus during the feeding assays (no association was observed in the surveys), but they exhibited a clear tendency to feed on D. occidentalis colonies at higher rates. That preference, or tendency, disappeared when given blended colony samples. This shift when given blended colonies may be attributed to a lack of tunic structure/thickness or it may be that stimulants that are dormant in intact B. violaceus colonies are released when colonies are blended; however, no palatability studies of Botrylloides spp. have indicated the presence of such potential chemical stimulants and have, instead, detected chemical defenses against a fish predator, showing that chemical defense in this instance may outweigh the presence of any stimulants (Pisut \& Pawlik 
2002). A chemical change known to occur when ascidians are damaged, is an increase in $\mathrm{pH}$ (Stoecker 1980a). This acidity is generally recognized as a potential defense of ascidians (Pisut \& Pawlik 2002). Other studies of ascidian palatability implicate tunic toughness as a key defense against predation in systems that lack fish predators with strong jaws (Koplovitz et al. 2009, Koplovitz \& McClintock 2011). Chemical and physical defenses are considered to be interactive (López-Legentil 2006), making it difficult to identify a singular effective defense. Despite potential interactive effects or the presence of stimulants, the fact that blending the tunic in the blended assay eliminated the significant difference found in feeding rates on the native versus non-native ascidian whole colony samples provides some indication that tunic structure/thickness may be an important factor in understanding predator avoidance or consumption of non-native ascidian species.

Another characteristic that may influence these predation rates on the native versus non-native ascidian is caloric content, which may be directly related to tunic thickness as tunics are composed of largely inorganic materials (Tarjuelo et al. 2002). Field surveys of predation on ascidians showed a significant difference with many documented instances of feeding on D. occidentalis, and no instances of the nudibranch feeding on B. violaceus. Evidence of $H$. crassicornis' ability to feed on B. violaceus was observed in the laboratory following a 24-hour starvation period. Hermissenda crassicornis is able to feed on $B$. violaceus but this ascidian was not the more palatable food. Of the other dock predators tested, kelp crabs (Pugettia producta) fed on D. occidentalis but the other species examined did not eat either ascidian. The predation 
rates of these suspended environment predators were significantly different between ascidian prey species (native D. occidentalis, non-native B. violaceus; Table 5).

\section{Benthic Predation}

Benthic predation patterns indicate a small degree of biotic resistance through consumption; however, further experiments need to be conducted to understand the overall influence benthic predators have on ascidian distributions in Charleston, Oregon and elsewhere. Botrylloides violaceus is rarely if ever found as part of the benthos, despite presence in marinas (Hewitt 1993). Biotic resistance in benthic habitats may be offered by Pagurus granosimanus, as they feed on B. violaceus at significantly higher rates than on $D$. occidentalis. Although $H$. oregonensis fed on $B$. violaceus, it fed on $D$. occidentalis at higher rates, indicating that resistance is not uniform across species in the benthic community. Other studies of crustacean predation in the fouling community have shown that predation may be indiscriminate in larval stages (Dumont et al. 2011a), suggesting that biotic resistance through consumption is dependent on the life stage of prey organisms. My study utilized adult ascidian colonies; however, to fully understand benthic environment interactions, studies highlighting predation on ascidian larvae and newly settled ascidian colonies need to be conducted.

\section{Palatability}

The native ascidian Distaplia occidentalis is more palatable than the non-native ascidian Botrylloides violaceus. It is possible that a greater number of caloric content samples would yield a statistically significant difference showing that D. occidentalis 
colonies do have greater overall caloric content than B. violaceus. This trend, however, is still apparent given the average caloric content analysis (Figure 2). I assessed the influence of chemical and structural defenses on predation rates, and the fact that no significant differences were found in predation rates between native versus non-native ascidians once they were ground up and a difference only when whole, indicates tunic structure or thickness is potentially a key characteristic reducing predation. Paired with the caloric content analysis, Distaplia occidentalis may be physically easier to feed on for soft-bodied predators, and generally contains more organic material. Botrylloides violaceus has a thicker or tougher tunic and lower caloric content and is not as attractive as food. These characteristics may be important in assessing an ascidian's ability to establish and persist on novel floating structure habitat for fouling species.

\section{Indirect Facilitation}

It is clear that predation on suspended structures is not providing biotic resistance, and may in fact be indirectly facilitating the growth of the most abundant non-native ascidian through depredation of the most abundant native ascidian in Charleston Marina,

Oregon (Table 5, Figure 3a, 3b). My work also indicates that healthy populations of Pagurus spp. could be an important factor limiting spread of B. violaceus to more benthic regions. Biotic resistance through predation has been found elsewhere, to limit the distributions of ascidian species to suspended, artificial structures (Dumont et al. 2011a, Simkanin et al. 2013, Forrest et al. 2013). These studies, however, did not look for indirect facilitation through consumption of competing ascidian species within the suspended environment. The process of indirect facilitation of the growth of non-native 
species through predation on a competing species has been documented in other habitats, as in Grosholz (2005) where European green crabs, Carcinus maenas, exerted indirect facilitation through predation on the native bivalves, thereby freeing space and resources for the non-native clam, Gemma gemma. In Morro Bay, California, native predators, sea otters and sea stars, preyed on suspended structure mussel species, freeing space for the non-native bryozoan, Watersipora subtorquata (Needles et al. 2015), also showing indirect facilitation through predation on competing species in the fouling community. Through this study, I provide quantitative measurements of palatability characteristics and the influence of palatability characteristics of the non-native ascidian, B. violaceus, on predator-prey interactions. I have shown that indirect facilitation through predation of native ascidians may be a factor influencing the success of non-native ascidians in suspended habitats. The predation by benthic hermit crabs also suggested benthic resistance may limit the spread of the non-native Botryllid ascidians to these habitats despite indirect facilitation on the docks.

\section{Conclusion}

The palatability characteristics of Botrylloides violaceus, especially caloric content and tunic structure or thickness, may indicate this species' invasiveness in the Charleston Marina, Oregon fouling community across benthic and suspended habitats. Community invasibility, however, may be dependent on habitat type, the benthos or suspended structures, and the predators found there (Dumont et al. 2011a). The predators of ascidians on suspended structures may indirectly facilitate invasion of $B$. violaceus by 
preying on the most abundant native ascidian, a putative competitor for space (Tyrrell \& Byers 2007, Stachowicz et al. 2002). Non-native species are not often found on the open coast, indicating that this pattern may not be found in more pristine habitats (Wasson et al. 2005), but may be found in other marinas. In particular, marina infrastructure near natural rocky habitat as opposed to a more sedimentary benthos, is more likely to have a competitive interaction between native and non-native fouling species (Airoldi et al. 2015). Non-natives are 2-3 times more abundant on infrastructure near sandy areas than rocky habitats and have also been found to harbor almost no native species (Airoldi et al. 2015). Therefore, indirect facilitation through predation on native species is more likely to occur on artificial structures near rocky benthic habitats.

Novel ecosystems are systems where species occur in combinations that did not previously exist, creating new species interactions; these systems include marinas and their suspended structures, which are a direct result of human action altering estuarine ecosystems (Hobbs et al. 2006). Coastal development along the temperate Pacific is associated with an increase in the number of marine non-native species (Wonham \& Carlton 2005). As human development continues to increase, so will the extent of novel ecosystems, increasing non-native species abundance and, subsequently, instances of such patterns of indirect facilitation or resistance.

Instances of biotic resistance to ascidians on rocky substrates have been observed through other studies, and this kind of interaction between a non-native fouling species and benthic predators is likely to be found anywhere close to human populations, shipping, and aquaculture. Other factors influencing where patterns of indirect 
facilitation and biotic resistance may be found include latitude and community ecology components, like the extent to which a predator is a specialist or generalist. In general predation pressure is heavier in the tropics and so is biotic resistance through predation (Freestone et al. 2013). In fact, the impact of predation on non-native species richness is three times greater in the tropics than in temperate regions (Freestone et al. 2013). Consequently, more non-native species are found in temperate regions (Ruiz et al. 2015), suggesting a greater likelihood of instances of indirect facilitation in temperate regions than tropical. Shea \& Chesson (2002) describe the importance of integrating community ecology theory and invasions ecology to better understand and predict invasive species interactions. If the predators that typically inhabit suspended structures are highly specialist on native prey species, this increases the opportunity for indirect facilitation and increases the community's overall invasibility (Shea \& Chesson 2002). Predators that are more generalist may offer a greater amount of resistance to invasion (Shea \& Chesson 2002). These native, generalist predators could be important in regulating nonnative species and preventing their spread to other habitats, and they should, therefore, be monitored or protected through management (Carlsson et al. 2009). This study expands knowledge of how novel, non-native species interact with recipient communities, informing the development and implementation of control strategies, as well as how ecosystems function (Sax et al. 2007). 


\section{Chapter 4: Conclusion}

Non-native ascidians and other non-native marine species present ecological and regulatory challenges to managers and scientists. To address these challenges, science and management must cooperate for the development of regulatory and assessment standards. This cooperation will yield opportunities for relevant experiments to be conducted alongside on-the-ground management efforts, solidifying management outcomes (Williams \& Grosholz 2008). As an example, ballast water discharge standards enforced by the U.S. Coast Guard could be more strongly tested and refined through science, enhancing management efficacy (Albert et al. 2013). Ballast water discharge standards also provide a good example or platform for coordinated biofouling management. Due to the fact that invasive species do not respect state lines, managers need to work together to coordinate effective, proactive regulation of vectors, which is not limited to ballast water. Combating the threat of non-native species spread requires informed risk assessment, which may be done using distribution models (Williams \& Grosholz 2008). These models are informed by science and may incorporate relevant biotic interaction data such as a habitat's level of biotic resistance. For these reasons, I addressed management gaps of non-native fouling species vectors in Oregon and Washington through a Regional Biofouling Management Plan and contributed to the knowledge of biotic interactions between non-native ascidians and a human-mediated recipient community on the Oregon coast through scientific surveys and experiments. 
Building off the current momentum to address the threat of non-native ascidians on the West Coast, the development of the Regional Biofouling Management Plan has successfully brought non-native fouling species, as a group, and their multiple vectors to the attention of Oregon and Washington managers and fostered the initial processes for a coordinated coastal plan. More work is needed to fully assess risks associated with vectors, but the survey of recreational boater movement and cleaning behaviors in Oregon provides a foundation for future efforts along with previous assessments completed in Washington, California, and Hawaii. This document also serves as a central source, or starting point for relevant management plans and scientific literature that offer specific to more general recommendations to managers dealing with non-native species. This plan also lays out the structure for why and how such coordinated multi-species, vector management could occur. As states recognize and address authority gaps, the biofouling management framework will be used to guide the conversation between managers as various stages of coastal management are realized.

My experimental work adds to a larger body of studies looking at immediate interactions of non-native species and provides information on the interactions between prey characteristics, habitat, and predator community composition that may ultimately be useful in understanding the persistence of non-native ascidians on marina infrastructure and the likelihood of escape to surrounding habitats. It may also inform future studies on the implications of variable predator diversity across different substrata. This study successfully identifies a source of biotic resistance as well as a highly specialist predator at one site on the Oregon coast. Further studies incorporating a range of sites or taxa 
would allow for more comprehensive findings. In addition, surveys combined with laboratory work provide a compelling case for the invasive characteristics of Botrylloides violaceus as well as the overall invasibility of benthic versus suspended structure habitats. Further field experiments may solidify findings related to the overall distributions of the ascidian species and could include experimental plates in each habitat with some open to predators and some plates in predator exclusion cages (similar to Shinen et al. 2009). Predators identified (through field observation or laboratory tests) as sources of biotic resistance, could become a focus of monitoring efforts in assessing habitat invasibility or health. Predator function (generalist to specialist) in a given habitat will also be important to assess potential for biotic resistance. This kind of study could be used to create a model of biotic resistance to invasion by ascidians (if other sites and their relevant predator species are incorporated) allowing for the prediction of distributions that may be influenced by biotic resistance and healthy predator populations.

The management plan I wrote and the scientific study I conducted have expanded understanding of non-native fouling species issues and ecology. Next steps in the coastal biofouling plan include applying to state legislatures, where necessary, for designation of authority to implement fouling regulatory standards for various vectors as well as defining clear authorities for response activities. Williams \& Grosholz (2008) explain how management and science ought to work together to address marine invasive species and maintain momentum, calling for greater cooperation between on-the-ground management efforts and ecological studies. In a human-mediated habitat without strong management presence and without the opportunity to work alongside long-term 
management efforts, my research builds on existing studies focusing on the immediate biotic interactions of fouling invasions. Together, these studies provide a base of knowledge from which distribution models may incorporate important biotic interactions such as biotic resistance, potentially allowing for the prioritization of management in habitats with low biotic resistance or facilitative interactions. Ultimately, reducing the spread of non-native fouling species through regional, vector-based management and understanding the interactions of those species that have already established will help mitigate the challenges coastal economies and ecosystems will contend with as species continue to spread along with continued anthropogenic movement and as communities shift due to climate change. 


\section{References}

Airoldi, L., X. Turon, S. Perkol-Finkel, and M. Rius. 2015. Corridors for aliens but not for natives: effects of marine urban sprawl at a regional scale. Diversity and Distributions 21(2015):755-768.

Albert, R. J., J. M. Lishman, and J. R. Saxena. 2013. Ballast water regulations and the move toward concentration-based numeric discharge limits. Ecological Applications 23:289-300.

Aldred, N., and A. S. Clare. 2014. Mini-review: impact and dynamics of surface fouling by solitary and compound ascidians. Biofouling 30:259-70.

Altieri, A. H., B. K. van Wesenbeeck, M. D. Bertness, and B. R. Silliman. 2010. Facilitation cascade drives positive relationship between native biodiversity and invasion success. Ecology 91(5):1269-1275.

Anderson, L. W. J. 2005. California's Reaction to Caulerpa taxifolia: A Model for Invasive Species Rapid Response. Biological Invasions 7:1003-1016.

Bailey, Sarah A. 2015. An overview of thirty years of research on ballast water as a vector for aquatic invasive species to freshwater and marine environments. Aquatic Ecosystem Health \& Management 4988:37-41.

Barnes, D. K. A., F. Galgani, R. C. Thompson, and M. Barlaz. 2009. Accumulation and fragmentation of plastic debris in global environments. Philosophical Transactions of the Royal Society-Biological Sciences 364(1526):1985-1998.

Bax, N., J. T. Carlton, A. Mathews-Amos, R. L. Haedrich, F. G. Howarth, J. E. Purcell, A. Reiser, and A. Gray. 2001. The control of biological invasions in the world's oceans. Conservation Biology 15(5):1234-1246.

Bax, N., A. Williamson, M. Aguero, E. Gonzalez, and W. Geeves. 2003. Marine invasive alien species: a threat to global biodiversity. Marine Policy 27:313-323.

Brey, T., H. Rumohr, and S. Ankar. 1988. Energy content of macrobenthic invertebrates - General conversion factors from weight to energy. Journal of Experimental Marine Biology and Ecology 117:271-278.

Bruno, J. F., J. J. Stachowicz, and M. D. Bertness. 2003. Inclusion of facilitation into ecological theory. Trends in Ecology \& Evolution 18:119-125. 
Buhle, E. R., M. Margolis, and J. L. Ruesink. 2005. Bang for buck: cost-effective control of invasive species with different life histories. Ecological Economics 52(2005):355366.

Bullard, S. G., G. Lambert, M. R. Carman, J. Byrnes, R. B. Whitlatch, G. Ruiz, R. J. Miller, L. Harris, P. C. Valentine, J. S. Collie, J. Pederson, D. C. McNaught, a. N. Cohen, R. G. Asch, J. Dijkstra, and K. Heinonen. 2007. The colonial ascidian Didemnum sp. A: Current distribution, basic biology and potential threat to marine communities of the northeast and west coasts of North America. Journal of Experimental Marine Biology and Ecology 342:99-108.

Carlsson, N., O. Sarnelle, and D. L. Strayer. 2009. Native predators and exotic prey-an acquired taste? Frontiers in Ecology \& Environment 7(10):525-532.

Carlton, James T. 1989. Man's role in changing the face of the ocean: Biological invasions and implications for conservation of near-shore environments. Conservation Biology 3:265-273.

Carlton, J. T., J. B. Geller, M. L. Reaka-kudla, and E. A. Norse. 1999. Historical extinctions in the sea. Annual Review of Ecology and Systematics 30:515-538.

Catford, J. A., R. Jansson, and C. Nilsson. 2009. Reducing redundancy in invasion ecology by integrating hypotheses into a single theoretical framework. Diversity and Distributions 15:22-40.

Chanas, B., and J. R. Pawlik. 1995. Defenses of Caribbean sponges against predatory reef fish. 11. Spicules, tissue toughness, and nutritional quality. Marine Ecology Progress Series 127:195-211.

Chapman, J. W., T. W. Miller, and E. V. Coan. 2003. Live seafood species as recipes for invasion. Conservation Biology 17.5:1386-1395.

Clark, G. F., and E. L. Johnston. 2009. Propagule pressure and disturbance interact to overcome biotic resistance of marine invertebrate communities. Oikos 118:16791686.

Clean Marina Washington. 2014. http://www.cleanmarinawashington.org/

Cohen, A. N., and J. T. Carlton. 1998. Accelerating invasion rate in a highly invaded estuary. Science 279:555-558.

Collin, S. B., K. MacIver, and R. Shucksmith. 2015. A Biosecurity Plan for the Shetland Islands. 
Commonwealth of Australia. 2013. National System for the Prevention and Management of Marine Pest Incursions. http://www.marinepests.gov.au/nationalsystem/Pages/default.aspx

Darbyson, E., A. Locke, J. M. Hanson, and J. H. M. Willison. 2009. Marine boating habits and the potential for spread of invasive species in the Gulf of St. Lawrence. Aquatic Invasions 4(1):87-94.

Darling, J. A., and A. R. Mahon. 2011. From molecules to management: Adopting DNAbased methods for monitoring biological invasions in aquatic environments. Environmental Research 111(7):978-988.

Davidson, I. C., C. W. Brown, M. D. Sytsma, and G. M. Ruiz. 2009. The role of containerships as transfer mechanisms of marine biofouling species. Biofouling 25.7: 645-655.

Davidson, I., C. Zabin, A. Chang, C. Brown, M. Sytsma, and G. Ruiz. 2010. Recreational boats as potential vectors of marine organisms at an invasion hotspot. Aquatic Biology 11:179-191.

Davidson, I., G. Ashton, C. Zabin, G. Ruiz. 2012. Aquatic invasive species vector risk assessments: The role of fishing vessels as vectors for marine and estuarine species in California. Report to the California Ocean Science Trust. Oakland, California. $70 \mathrm{pp}$

Davidson, I., C. Zabin, G. Ashton, and G. M. Ruiz. 2014. An assessment of marine biofouling introductions to the Puget Sound region of Washington State final report. Aquatic Bioinvasion Research \& Policy Institute 111pp.

deRivera, C. E., G. M. Ruiz, A. H. Hines, and P. Jivoff. 2005. Biotic resistance to invasion: native predator limits abundance and distribution of an introduced crab. Ecology 86(12):3364-3376.

DFO. 2013. Science advice from a risk assessment of five sessile tunicate species. DFO Can. Sci. Advis. Sec. Sci. Advis. Rep. 2012/049.

Dijkstra, J., H. Sherman, and L. G. Harris. 2007. The role of colonial ascidians in altering biodiversity in marine fouling communities. Journal of Experimental Marine Biology and Ecology 342(1):169-171.

Draheim, R., R. Boatner, G. Dolphin, and L. DeBruyckere. 2013. Oregon Dreissenid mussel rapid response plan. Center for Lakes and Reservoirs 35pp. 
Dumont, C. P., C. F. Gaymer, and M. Theil. 2011a. Predation contributes to invasion resistance of benthic communities against the non-indigenous tunicate Ciona intestinalis. Biol. Invasions 13:2023-2034.

Dumont, C. P., L. G. Harris, and C. F. Gaymer. 2011b. Anthropogenic structures as a spatial refuge from predation for the invasive bryozoan Bugula neritina. Marine Ecology Progress Series 427:95-103.

Eissinger, Ann. 2009. Marine Invasive Species Identification Guide. Puget Sound Marine Invasive Species Volunteer Monitoring Program http://www.psp.wa.gov/downloads/ANS/MISM_Online.pdf

Elton, Charles S. 1958. The ecology of invasions by animals and plants. Methuen, London 181pp.

Epelbaum, A., C. M. Pearce, D. J. Barker, A. Paulson, and T. W. Therriault. 2009. Susceptibility of non-indigenous ascidian species in British Columbia (Canada) to invertebrate predation. Marine Biology 156:1311-1320.

Finnoff, D., J. F. Shogren, B. Leung, and D. Lodge. 2007. Take a risk: Preferring prevention over control of biological invaders. Ecological Economics 62:216-222.

Floerl, O., G. J. Inlglis, K. Dey, and A. Smith. 2009. The importance of transport hubs in stepping-stone invasions. Journal of Applied Ecology 46(1):37-45.

Fofonoff, P. W., G. M. Ruiz, B. Steves, J. T. Carlton. 2003a."In ships or on ships? Mechanisms of transfer and invasion for nonnative species to the coasts of North America." Invasive species: vectors and management strategies 152-182.

Fofonoff, P. W., G. M. Ruiz, B. Steves, \& J. T. Carlton. 2003b. National Exotic Marine and Estuarine Species Information System. http://invasions.si.edu/nemesis/. Access Date: $12-\mathrm{Feb}-2015$

Forrest, B. M., L. M. Fletcher, J. Atalah, R. F. Piola, and G. A. Hopkins. 2013. Predation limits spread of Didemnum vexillum into natural habitats from refuges on anthropogenic structures. Plos One 8.

Freestone, A. L., G. M. Ruiz, and M. E. Torchin. 2013. Stronger biotic resistance in tropics relative to temperate zone: Effects of predation on marine invasion dynamics. Ecology 94:1370-1377.

Gollasch, S. 2002. The importance of ship hull fouling as a vector of species introductions into the North Sea. Biofouling 18:105-121.

Gotelli, N. J., and A. M. Ellison. 2004. A primer of ecological statistics. Sinauer Associates, Inc. 507pp. 
Great Lakes Commission. 2014. Invasive Species: Internet Trade of Aquatic Invasive Species http:/glc.org/projects/invasive/internet-trade-ais/

Grey, Erin K. 2011. Relative effects of environment and direct species interactions on the population growth rate of an exotic ascidian. Oecologia 166:935-947.

Grosholz, Edwin D. 2005. Recent biological invasion may hasten invasional meltdown by accelerating historical introductions. Proceedings of the National Academy of Sciences 102(4):1088-1091.

Grover, James P. 1994. Assembly rules for communities of nutrient-limited plants and specialist herbivores. The American Naturalist 143(2):258-282.

Hastings, A., R. J. Hall, and C. M. Taylor. 2006. A simple approach to optimal control of invasive species. Theoretical Population Biology 70:431-5.

Herborg, L. M., P. O'Hara, and T. W. Therriault. 2009. Forecasting the potential distribution of the invasive tunicate Didemnum vexillum. Journal of Applied Ecology 46(1):64-72.

Hewitt, Chad L. 1993. Marine biological invasions: The distributional ecology and interactions between native and introduced encrusting organisms. Department of Biology and the Graduate School of the University of Oregon 301pages.

Hobbs, R. J., S. Arico, J. Aronson, J. S. Baron, P. Bridgewater, V. A. Cramer, P. R. Epstein, J. J. Ewel, C. A. Klink, A. E. Lugo, D. Norton, D. Ojima, D. M. Richardson, E. W. Sanderson, F. Valladares, M. Vilà, R. Zamora, and M. Zobel. 2006. Novel ecosystems: Theoretical and management aspects of the new ecological world order. Global Ecology and Biogeography 15:1-7.

Holcombe, T. R., T. J. Stohlgren, and C. S. Jarnevich. 2010. From points to forecasts: Predicting invasive species habitat suitability in the near term. Diversity 2(5):738767.

Hulme, P. E. 2006. Beyond control: wider implications for the management of biological invasions. Journal of Applied Ecology 43:835-847.

Jerde, C. L., A. R. Mahon, W. L. Chadderton, and D. M. Lodge. 2011. "Sight-unseen" detection of rare aquatic species using environmental DNA. Conservation Letters $4(2): 150-157$.

Kennedy, T. A., S. Naeem, K. M. Howe, J. M. H. Knops, D. Tilman, and P. Reich. 2002. Biodiversity as a barrier to ecological invasion. Nature 417:636-638. 
Kimbro, D. L., B. S. Cheng, and E. D. Grosholz. 2013. Biotic resistance in marine environments. Ecology letters 16:821-33.

Kolar, C. S., and D. M. Lodge. 2001. Progress in invasion biology: predicting invaders. Trends in Ecology \& Evolution 16:199-204.

Koplovitz, G., J. McClintock, C. Amsler, and B. Baker. 2009. Palatability and chemical anti-predatory defenses in common ascidians from the Antarctic Peninsula. Aquatic Biology 7:81-92.

Koplovitz, G., and J. B. McClintock. 2011. An evaluation of chemical and physical defenses against fish predation in a suite of seagrass-associated ascidians. Journal of Experimental Marine Biology and Ecology 407:48-53.

Kubanek, J., D. E. Williams, E. D. de Silva, T. Allen, and R. J. Andersen. 1995. Cytotoxic alkaloids from the flatworm Prostheceraeus villatus and its tunicate prey Clavelina lepadiformis. Tetrahedron Letters 36:6189-6192.

Kulhanek, S. A., B. Leung, and A. Ricciardi. 2011. Using ecological niche models to predict the abundance and impact of invasive species: application to the common carp. Ecological Applications 21(1):203-213.

Lages, B. G., B. G. Fleury, C. E. L. Ferreira, and R. C. Pereira. 2006. Chemical defense of an exotic coral as invasion strategy. Journal of Experimental Marine Biology and Ecology 328:127-135.

Lambert, Gretchen. 2007. Invasive sea squirts: a growing global problem. Journal of Experimental Marine Biology and Ecology 342:3-4.

Lengyel, N., J. S. Collie, and P. C. Valentine. 2009. The invasive colonial ascidian Didemnum vexillum on Georges Bank - Ecological effects and genetic identification. Aquatic Invasions 4:143-152.

Leung, B., D. M. Lodge, D. Finnoff, J. F. Shogren, M. A. Lewis, and G. Lamberti. 2002. An ounce of prevention or a pound of cure: bioeconomic risk analysis of invasive species. Proceedings. Biological sciences / The Royal Society 269:2407-2413.

Levine, J. M., and C. M. D’Antonio. 1999. Elton revisited : a review of evidence linking diversity and invasibility 87:15-26.

Levine, J. M., P. B. Adler, and S. G. Yelenik. 2004. A meta-analysis of biotic resistance to exotic plant invasions. Ecology Letters 7:975-989. 
Lindquist, N., M. E. Hay, and W. Fenical. 1992. Defense of ascidians and their conspicuous larvae: Adult vs. larval chemical defenses. Ecological Monographs 62:547-568.

Locke, A., J. M. Hanson, K. M. Ellis, J. Thompson, and R. Rochette. 2007. Invasion of the southern Gulf of St. Lawrence by the clubbed tunicate (Styela clava Herdman): Potential mechanisms for invasions of Prince Edward Island estuaries. Journal of Experimental Marine Biology and Ecology 342:69-77.

Lockwood, J. L., M. F. Hoopes, and M. P. Marchetti. 2013. Invasion Ecology. WileyBlackwell.

Lodge, D. M., S. Williams, H. J. MacIsaac, K. R. Hayes, B. Leung, S. Reichard, R. N. Mack, P. B. Moyle, M. Smith, D. A. Andow, J. T. Carlton, and A. McMichael. 2006. Biological invasions: Recommendations for U.S. policy and management. Ecological Applications: ESA Report 16(6):2035-2054.

López-Legentil, S., X. Turon, and P. Schupp. 2006. Chemical and physical defenses against predators in Cystodytes (Ascidiacea). Journal of Experimental Marine Biology and Ecology 332:27-36.

Mangin, Susan. 2011. The $100^{\text {th }}$ Meridian Initiative: a strategic approach to prevent the westward spread of zebra mussels and other aquatic nuisance species. U.S. Fish \& Wildlife Service 16pp.

Meacham, Pamela. 2001. Washington state aquatic nuisance species management plan. Washington Department of Fish \& Wildlife. Washington Aquatic Nuisance Species Coordinating Committee. 118pp.

Millar, R. H. 1971. The biology of ascidians. Advances in Marine Biology, 9 1-100.

Miller, A. W. and G. M. Ruiz. 2009. Differentiating successful and failed invaders: species pools and the importance of defining vector, source and recipient regions. Biological invasions in marine ecosystems. Springer Berlin Heidelberg 153-170.

Murray, C. C., E. A. Pakhomov, and T. W. Therriault. 2011. Recreational boating: A large unregulated vector transporting marine invasive species. Diversity and Distributions 17:1161-1172.

Naeem, S., J. M. Knops, D. Tilman, K. M. Howe, T. Kennedy, and S. Gale. 2000. Plant diversity increases resistance to invasion in the absence of covarying extrinsic factors. Oikos 91:97-108. 
National Geographic Society. 2014. BioBlitz http://www.nationalgeographic.com/explorers/projects/bioblitz/

Needles, L. A., J. S. Gosnell, G. T. Waltz, D. E. Wendt, and S. D. Gaines. 2015. Trophic cascades in an invaded ecosystem: native keystone predators facilitate a dominant invader in an estuarine community. Oikos 124:1282-1292.

Northern Territory Government. 2014. Vessel Inspections and Treatments. Department of Primary Industry \& Fisheries http://www.nt.gov.au/d/Fisheries/?Header=Vessel\%20Inspections

Nydam, M., and J. Stachowicz. 2007. Predator effects on fouling community development. Marine Ecology Progress Series 337:93-101.

Occhipinti-Ambrogi, A., and D. Savini. 2003. Biological invasions as a component of global change in stressed marine ecosystems. Marine Pollution Bulletin 46(5): 542551.

Occhipinti-Ambrogi, Anna. 2007. Global change and marine communities: Alien species and climate change. Marine Pollution Bulletin 55(7-9):342-352.

Odate, S., and J. R. Pawlik. 2007. The role of vanadium in the chemical defense of the solitary tunicate, Phallusia nigra. Journal of Chemical Ecology 33:643-54.

Osman, R. W., and R. B. Whitlatch. 1995. The influence of resident adults on recruitment: a comparison to settlement. Journal of Experimental Marine Biology and Ecology 190:169-198.

Parker, J., D. Burkepile, and E. Merk. 2006. Opposing effects of native and exotic herbivores on plant invasions 311:1-7.

Paul, Michael. 2011. Biofouling threats associated with shipping traffic to Oregon waterways. Oregon Department of Environmental Quality 36pp.

Paul, V. J., N. Lindquist, and W. Fenical. 1990. Chemical defenses of the tropical ascidian Atapozoa spp. and its nudibranch predators. Marine Ecology Progress Series 59:109-118.

Pawlik, J. R., B. Chanas, and J. Robert. 1995. Defenses of Caribbean sponges against predatory reef fish. I. Chemical deterrency. Marine Ecology Progress Series 127:183-194. 
Pérez-Portela, R., and X. Turon. 2007. Prey preferences of the polyclad flatworm Prostheceraeus roseus among Mediterranean species of the ascidian genus Pycnoclavella. Hydrobiologia 592:535-539.

Peters, J. A., and D. M. Lodge. 2009. Invasive species policy at the regional level: a multiple weak links problem. Fisheries 34(8):373-381.

Pisut, D. P., and J. R. Pawlik. 2002. Anti-predatory chemical defenses of ascidians: secondary metabolites or inorganic acids? Journal of Experimental Marine Biology and Ecology 270:203-214.

Pleus, A., L. LeClair, J. Schultz, and G. Lambert. 2008. 2007-09 tunicate management plan. Washington State Department of Fish \& Wildlife. Aquatic Invasive Species Unit 64pp.

Priesler, R., K. Wasson, W. Wolff, and M. Tyrrel. 2009. Invasions of estuaries versus the adjacent open coast: a global perspective. Biological Invasions in Marine Ecosystems. Springer-Verlag, Berlin: 587-617.

Rosa, M., B. A. Holohan, S. E. Shumway, S. G. Bullard, G. H. Wikfors, S. Morton, and T. Getchis. 2013. Biofouling ascidians on aquaculture gear as potential vectors of harmful algal introductions. Harmful Algae 23:1-7.

Ruiz, G. M., P. W. Fofonoff, J. T. Carlton, M. J. Wonham, and A. H. Hines. 2000. Invasion of coastal marine communities in North America: apparent patterns, processes, and biases. Annual Review of Ecology and Systematics 31:481-531.

Ruiz, G. M., and J. T. Carlton. 2003. Invasion vectors: a conceptual framework for management. Invasive species: vectors and management strategies. 459-504.

Ruiz, G. M., M. E. Torchin, and K. Grant. 2009. Using the Panama Canal to Test Predictions about Tropical Marine Invasions.

Ruiz, G. M., P. W. Fofonoff, B. Steves, S. F. Foss, and S. N. Shiba. 2011. Marine invasion history and vector analysis of California: a hotspot for western North America. Diversity and Distributions 17(2):362-373.

Ruiz, G. M., C. Zabin, G. V. Ashton, M. Campbell, I. C. Davidson, L. G. Eldredge, P. W. Fofonoff, C. L. Hewitt, and M. Minton. 2014. Regional biosecurity plan for Micronesia and Hawaii, volume III. University of Guam and the Secretariat of the Pacific Community 474pp. 
Ruiz, G. M., P. W. Fofonoff, and J. T. Carlton. 2015. Invasion history and vector dynamics in coastal marine ecosystems: A North American perspective. Aquatic Ecosystem Health \& Management 18(3):299-311.

Sax, D. F., J. J. Stachowicz, J. H. Brown, J. F. Bruno, M. N. Dawson, S. D. Gaines, R. K. Grosberg, A. Hastings, R. D. Holt, M. M. Mayfield, M. I. O'Connor, and W. R. Rice. 2007. Ecological and evolutionary insights from species invasions. Trends in Ecology \& Evolution 22:465-71.

Schultz, M. P., J. A. Bendick, E. R. Holm, and W. M. Hertel. 2011. Economic impact of biofouling on a naval surface ship. Biofouling 27:87-98.

Shea, K., and P. Chesson. 2002. Community ecology theory as a framework for biological invasions. TRENDS in Ecology \& Evolution 17:170-176.

Shinen, J., S. Morgan, and A. Chan. 2009. Invasion resistance on rocky shores: direct and indirect effects of three native predators on an exotic and a native prey species. Marine Ecology Progress Series 378:47-54.

Simkanin, C., I. C. Davidson, J. F. Dower, G. Jamieson, and T. W. Therriault. 2012. Anthropogenic structures and the infiltration of natural benthos by invasive ascidians. Marine Ecology 33:499-511.

Simkanin, C., J. F. Dower, N. Filip, G. Jamieson, and T. W. Therriault. 2013. Biotic resistance to the infiltration of natural benthic habitats: Examining the role of predation in the distribution of the invasive ascidian Botrylloides violaceus. Journal of Experimental Marine Biology and Ecology 439:76-83.

Simoncini, M., and R. J. Miller. 2007. Feeding preference of Strongylocentrotus droebachiensis (Echinoidea) for a dominant native ascidian, Aplidium glabrum, relative to the invasive ascidian Botrylloides violaceus. Journal of Experimental Marine Biology and Ecology 342:93-98.

Sorte, C. J. B., S. L. Williams, and R. A. Zerebecki. 2010. Ocean warming increases threat of invasive species in a marine fouling community. Ecology 91(8):2198-2204.

Stachowicz, J., and N. Lindquist. 1997. Chemical defense among hydroids on pelagic Sargassum: predator deterrence and absorption of solar UV radiation by secondary metabolites. Marine Ecology Progress Series 155:115-126.

Stachowicz, J. J., R. B. Whitlatch, and R. W. Osman. 1999. Species diversity and invasion resistance in a marine ecosystem. Science 286:1577-1579. 
Stachowicz, J. J., H. Fried, R. W. Osman, and R. B. Whitlatch. 2002. Biodiversity, invasive resistance, and marine ecosystem function: reconciling pattern and process. Ecology 83:2575-2590.

State of Alaska. 2015. Invasive Species. Alaska Department of Fish and Game. http://www.adfg.alaska.gov/index.cfm?adfg=invasive.main

State of Oregon. 2014. Environmental Programs. Oregon State Marine Board. http://www.oregon.gov/OSMB/boater-info/Pages/Environmental.aspx

Stoecker, Diane. 1978. Resistance of a tunicate to fouling. The Biological Bulletin 155:615-626.

Stoecker, Diane. 1980a. Chemical defenses of ascidians against predators. Ecology 61(6):1327-1334.

Stoecker, D. 1980b. Relationships between chemical defense and ecology in benthic ascidians. Marine Ecology Progress Series 3:257-265.

Strecker, A.L., P.M. Campbell, and J.D. Olden. 2011. The aquarium trade as an invasion pathway in the Pacific Northwest. Fisheries 36(2):74-85.

Sylvester, F., O. Kalaci, B. Leung, A. Lacoursière-Roussel, C. C. Murray, F. M. Choi, M. A. Bravo, T. W. Therriault, and H. J. MacIsaac. 2011. Hull fouling as an invasion vector: can simple models explain a complex problem? Journal of Applied Ecology 48.2:415-423.

Thomson, Peter. 2014. Craft risk management standard: Biofouling on vessels arriving in New Zealand. Ministry for Primary Industries 8pp.

Takata, L., M. Falkner, and S. Gilmore. 2006. CSLC Report on Commercial Vessel Fouling in California. California State Lands Commission 1-76.

Tarjuelo, I., S. Lopez-Legentil, M. Codina, and X. Turon. 2002. Defence mechanisms of adults and larvae of colonial ascidians: patterns of palatability and toxicity. Marine Ecology Progress Series 235:103-115.

Tyrrell, M.C. and J.E. Byers. 2007. Do artificial substrates favor nonindigenous fouling species over native species? Journal of Experimental Marine Biology and Ecology 342:54-60.

United States Coast Guard 33 CFR 151.2025 
USDA-APHIS. 2015. Emerald Ash Borer Program Manual, Agrilus planipennis (Fairmaire) USDA-APHIS-PPQ. Emergency and Domestic Programs. Emergency Planning, Riverdale, Maryland.

Valentine, P. C., J. S. Collie, R. N. Reid, R. G. Asch, V. G. Guida, and D. S. Blackwood. 2007. The occurrence of the colonial ascidian Didemnum sp. on Georges Bank gravel habitat - Ecological observations and potential effects on groundfish and scallop fisheries. Journal of Experimental Marine Biology and Ecology 342:179181.

Verling, Emma, G. M. Ruiz, L. D. Smith, B. Galil, A. W. Miller, and K. R. Murphy. 2005. Supply-side invasion ecology: characterizing propagule pressure in coastal ecosystems. Proceedings of the Royal Society of London B: Biological Sciences 272(1569):1249-1257.

Vervoort, H. C., J. R. Pawlik, and W. Fenical. 1998. Chemical defense of the Caribbean ascidian Didemnum conchyliatum. Marine Ecology Progress Series 164:221-228.

Wasson, K., C. J. Zabin, L. Bedinger, M. C. Diaz, and J. S. Pearse. 2001. Biological invasions of estuaries without shipping: the importance of intraregional transport. Biological Conservation 102(2):143-153.

Wasson, K., K. Fenn, and J. Pearse. 2005. Habitat differences in marine invasions of Central California. Biological Invasions 7:935-948.

WCGA. 2010. Spartina eradication action coordination work plan. West Coast Governor's Agreement on Ocean Health 49pp.

Western Regional Panel on Aquatic Invasive Species. 2014. Documents: Summary document of invasive tunicates workshop 2014 http://www.fws.gov/answest/documents.html

Williams, S. L., and E. D. Grosholz. 2008. The Invasive Species Challenge in Estuarine and Coastal Environments: Marrying Management and Science. Estuaries and Coasts 31:3-20.

Williams, S.L., R. E. Crafton, R. E. Fontana, E. D. Grosholz, J. Pasari, and C. Zabin. 2012. Aquatic invasive species vector risk assessments: A vector analysis of the aquarium and aquascape ('Ornamental Species') trades in California. Report submitted to the California Ocean Science Trust.

Wonham, M.J., and J. T. Carlton. 2005. Trends in marine biological invasions at local and regional scales: the Northeast Pacific Ocean as a model system. Biological Invasions 7:369-392. 
Young, Craig M. 1986. Defenses and refuges: alternative mechanisms of coexistence between a predatory gastropod and its ascidian prey. Marine Biology 91:513-522.

Zabin, C. J., G. V Ashton, C. W. Brown, I. C. Davidson, M. D. Sytsma, and G. M. Ruiz. 2014. Small boats provide connectivity for nonindigenous marine species between a highly invaded international port and nearby coastal harbors 5:97-112. 


\section{Appendix A: Oregon Boater Behavioral Questionnaire}

This questionnaire was provided by Ian Davidson and was used to assess recreational boater cleaning and travel practices to inform biofouling risk assessment.

\begin{tabular}{l} 
Vessel Information \& Particulars \\
\begin{tabular}{|l|l|}
\hline Today's Date (Day/Month/Year): & \\
\hline Type of boat (check the appropriate box) & $\begin{array}{l}\text { Sailboat/Yacht } \square \\
\text { Fishing boat } \square \\
\text { Other } \square \text { Specify }\end{array}$ \\
\hline Boat length (feet) & $\begin{array}{l}\text { Home harbor marina name: } \\
\text { Home harbor town/city: }\end{array}$ \\
\hline $\begin{array}{l}\text { Where is the boat's home harbor? } \\
\text { Check not applicable if stored on land } \\
\text { when not in use. }\end{array}$ & $\begin{array}{l}\text { Home harbor state/country: } \\
\text { Not applicable } \square\end{array}$ \\
\hline
\end{tabular} \\
\hline
\end{tabular}

\section{Maintenance \& Anti-Fouling Paint}

When was the boat last hauled out for anti-fouling paint application?

What antifouling paint are you using?

If you don't know the brand of paint, check don't know and provide a description if possible (e.g. copper ablative, foul-release, etc) If the boat has no anti-fouling paint, check the appropriate box.

Since the last application of anti-fouling paint, has the boat been manually cleaned (scrubbed or brushed)? If yes, how many times has it been cleaned?

If it has been manually cleaned, what method was used? And where did cleaning occur? (check all that apply)

During a typical year, how many times is the hull of your boat cleaned? Please indicate if there is a difference between Summer and Winter periods.
Date (Month/Year):

Don't know $\square \quad$ Not applicable

Manufacturer/Company:

Product name:

Don't know

Generic description (if possible):

This boat does not have anti-fouling paint

\section{Yes}

Number of cleanings:

Date of most recent cleaning(M/Y):

No

Don't know

$\square$ In-water by a diver at my home marina

$\square$ In-water by a diver at another marina

Location (city/country):

Out-of-water / On land

Other (specify)

Number of Spring/Summer cleanings:

Number of Fall/Winter cleanings: 
Storage / Stationary Periods

Since it was last cleaned or painted, what is the longest time that the boat has been stationary inwater? (i.e. moored with no voyages) Where was this location? Check home port if this was the case.

Duration in one place:

End Date (Month/Year):

Harbor Name:

City:

State/Country:

Or

Home Port

\section{Recent Voyage Information}

Since the boat was last removed from the water (for paint application or storage), how many boat trips has it been on? (a rough estimate is fine).

Which of these options best describes the types of boat trips this boat has been on over the last 12 months?

Check multiple boxes if appropriate. Indicate how many of each trip-type was taken in the last year (a rough estimate is fine).

Check this box if no trips were taken in the last year

For trips in the past $\mathbf{1 2}$ months that involved overnight stays at other marinas (not your home marina), please provide some information on the locations and timing of those trips.

We have included space here for six of your most recent visits to locations away from your home marina.

If there are more, or if these places were all part of a voyage route to a certain destination, please tick this box $\square$ and use empty space to describe the ultimate destination or additional marinas/cities visited during the overall trip.

Number of boat trips:

I made local trips with no overnight stays outside of my home marina. \# of trips:

$\square$ I made trips that included overnight stays at other marinas in Oregon. \# of trips:

$\square$ I made trips that included overnight stays at other marinas outside of Oregon. \# of trips:

\section{Harbor Name:}

City:

State/Country:

Date $(\mathrm{D} / \mathrm{M} / \mathrm{Y})$ :

Harbor Name:

City:

State/Country:

Date (D/M/Y):

Harbor Name:

City:

State/Country:

Date (D/M/Y):

Harbor Name:

City:

State/Country:

Date (D/M/Y):

Harbor Name:

City:

State/Country:

Date (D/M/Y):

Harbor Name:

City:

State/Country:

Date $(\mathrm{D} / \mathrm{M} / \mathrm{Y})$ : 


\section{Optional Information for entry to the PRIZE DRAWING}

We do not require your name or contact information, but if you wish to be entered to the prize drawing for a \$200 gift voucher for Englund Marine, please return this survey by September $\mathbf{1}^{\text {st }}, \mathbf{2 0 1 5}$ and include your name and at least one point of contact below.

Thank you very much for your participation in this survey.

Name:

Email Address:

Phone Number: 


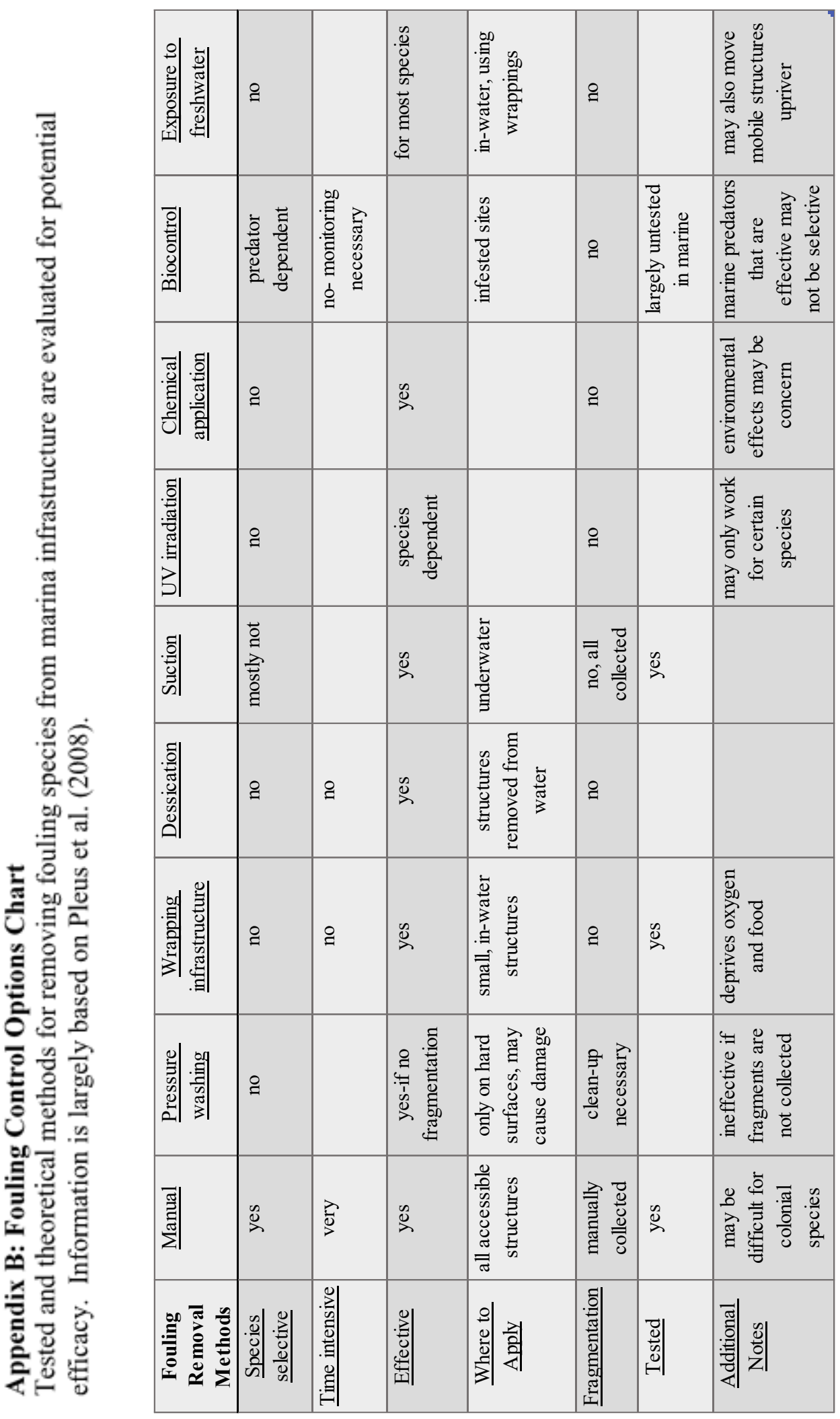


